\section{Pacific Northwest}

National Laboratory

Operated by Battelle for the

U.S. Department of Energy

\title{
Spills on Flat Inclined Pavements
}

\author{
C. S. Simmons \\ J. M. Keller \\ J. L. Hylden
}

March 2004

Prepared for the U.S. Department of Energy

under Contract DE-AC06-76RL01830 


\title{
DISCLAIMER
}

This report was prepared as an account of work sponsored by an agency of the United States Government. Neither the United States Government nor any agency thereof, nor Battelle Memorial Institute, nor any of their employees, makes any warranty, express or implied, or assumes any legal liability or responsibility for the accuracy, completeness, or usefulness of any information, apparatus, product, or process disclosed, or represents that its use would not infringe privately owned rights. Reference herein to any specific commercial product, process, or service by trade name, trademark, manufacturer, or otherwise does not necessarily constitute or imply its endorsement, recommendation, or favoring by the United States Government or any agency thereof, or Battelle Memorial Institute. The views and opinions of authors expressed herein do not necessarily state or reflect those of the United States Government or any agency thereof.

\author{
PACIFIC NORTHWEST NATIONAL LABORATORY \\ operated by \\ BATTELLE \\ for the \\ UNITED STATES DEPARTMENT OF ENERGY \\ under Contract DE-ACO6-76RLO183O
}

This document was printed on recycled paper. 
PNNL-14577

\title{
Spills on Flat Inclined Pavement
}

\author{
C. S. Simmons \\ J. M. Keller \\ J. L. Hylden
}

March 2004

Prepared for

the U.S. Department of Energy

under Contract DE-AC06-76RL01830

Pacific Northwest National Laboratory

Richland, Washington 99352 


\section{Summary}

Spills are important indicators of human activity. Spills persist for a period of time (hours, days, weeks) after an event and provide an opportunity to detect transient activities after the fact. Even with panchromatic imagery, it is easy to detect a spill from the change in the index of refraction (dark spots) on the ground. This report looks at the relationship between the size of a spill area and the volume of material spilled.

This report discusses general spill flow over the top millimeter of soil. Two chief areas of concern are addressed: a surface that is relatively impermeable and a subsurface that is permeable. The behavior of spills on a relatively impermeable surface is controlled by the wetting properties of the liquid and its interaction with the substrate. There is an initial rapid spreading followed by a creeping phenomenon. The spreading area in a permeable subsurface is mainly controlled by liquid viscosity and substrate permeability. In both situations, the initial liquid flow can be viewed as a "gravity current." This report focuses on spills on pavements, such as asphalt or concrete.

Equations are introduced that incorporate various factors, such as the volume of liquid spilled, the height of the liquid standing above the surface, the depth of liquid penetration below the surface, the porosity of the substrate, the force of gravity, the contact angle, and surface tension. An important factor is the interaction between the liquid and the surface, which is given by the contact angle.

The theory of spill size was tested for a cement pavement with several common liquids. Also, simulations were performed for hypothetical spills on ideal asphalt and concrete surfaces to determine the final areal extent of the spill and its relation to spill rate and spill quantity. These simulations were performed with a liquid pool equilibrium model. The size of the spill was largely determined by the contact angle, which can change with time as observed in the creeping behavior.

Coupling the spreading equilibrium model to the 2-D gravity current and Green-Ampt infiltration model (Appendix A) allows for spill progression and spill shape to be determined and provides the ability to consider surface roughness. A variety of spill scenarios were simulated, and the model was successfully validated. 


\section{Contents}

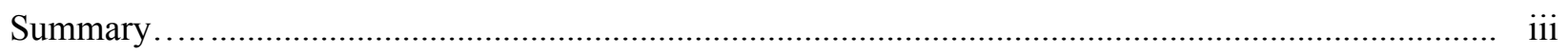

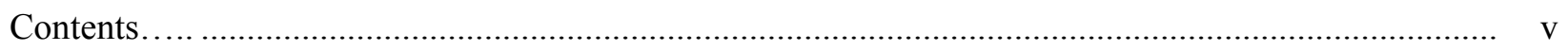

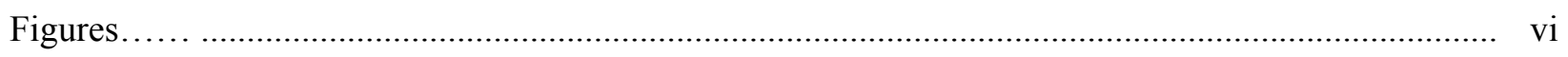

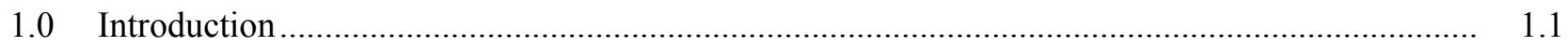

2.0 Equations Regulating Spills on Pavements .................................................................. 2.1

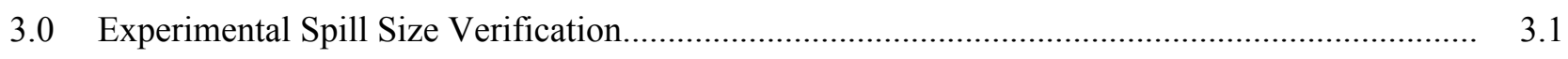

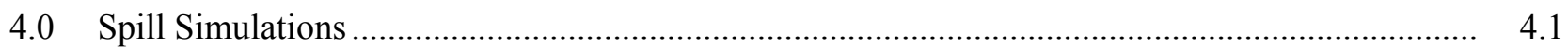

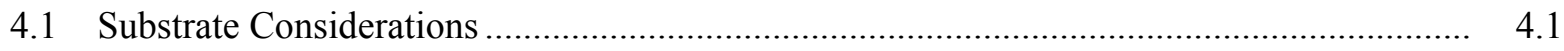

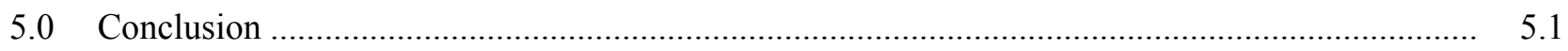

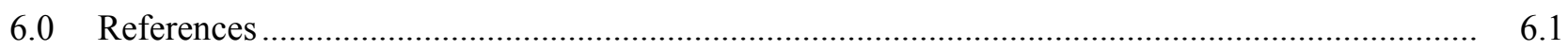

Appendix A Gravity Currents Combined with Infiltration ......................................................... A.1 


\section{Figures}

2.1. Spill Height Model for Liquid with Contact Angle to Substrate...................................................2.2

2.2. Contact-Angle Phenomena for Both Non-Wetting and Wetting Fluids ...................................... 2.4

3.1. Picture of Mineral Oil Spot on Smooth Concrete Floor. (Oil Volume is 40 ml.)........................ 3.1

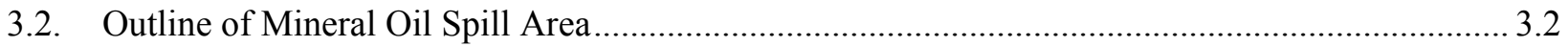

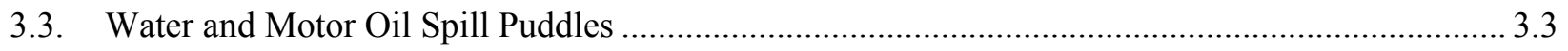

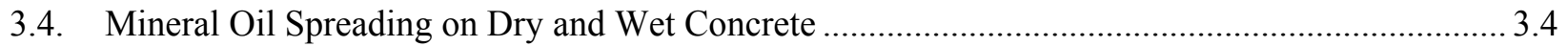

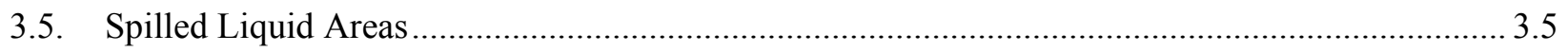

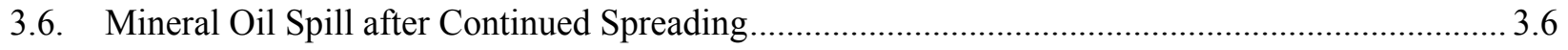

4.1. Model Representation of Surface Roughness ......................................................................... 4.2

4.2. Spatial Extent of Simulated $40 \mathrm{Ml}$ Mineral Oil Spill (Red) and Observed Coverage from Experiment (Black Line)

4.3. Spill Area as a Function of Total Spill Volume for 1) an Asphalt Surface at a One-Degree Slope and 2) a Concrete Surface at a One-Degree Slope ............................................................ 4.4

4.4. Simulated Mineral Oil Spill Spatial Extent as a Function of Slope ............................................ 4.5

\section{Tables}

2.1. Physical Properties of Select Chemicals of Interest .................................................................. 2.3

3.1. Sizes of Liquid Spills on Concrete Floor. Spill volume is $40 \mathrm{ml}$ in all cases.............................. 3.4

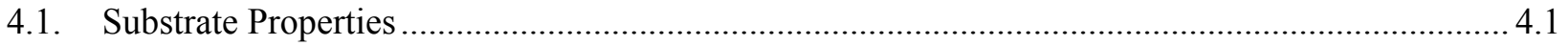

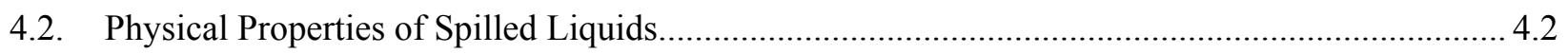

4.3. Simulated Spill Area and Spreading Time for a Mineral Oil Spill on Varying Slopes .................. 4.6

4.4. Simulated Spill Area and Spreading Time for a 55-Gal Mineral Oil Spill on a One-Degree Slope with Spilled Liquid Running off the Edge of the Simulated Domain ................................. 4.6

4.5. Calculated Equilibrium Spill Height and Spill Area Using the Measured (72.3 ${ }^{\circ}$ Contact Angle for Mineral Oil on Concrete and Additional Contact Angles. 


\subsection{Introduction}

Gaseous effluents are ephemeral by nature. They disperse within seconds to minutes as they mix with the atmosphere. Spills last longer, on the order of days to weeks. Theriault et al. studied contaminants on surface materials (Theriault et al. 2001), and Young has reported the presence of spills in remotely sensed data (Young 2001a, 2001b), but neither has systematically studied the phenomenology of spills. Hussein has studied the surface spreading of petroleum (Hussein et al. 2002) but not other materials. A large amount of hydrology work has focused on the transport of spills through the vadose zone of the soil. This series of reports is focused on general spill phenomenology in the top millimeter of soil.

This report describes the relationship between the amount of a spilled liquid and the visible surface area. There are two main situations of concern: 1) the surface is relatively impermeable (such as concrete or asphalt pavement) or 2) the subsurface is permeable (such as soil or gravel) and eventually imbibes the spilled liquid. Both situations have been called out as requirements.

The first situation is primarily controlled by wetting properties of the liquid and its interaction with the substrate. The inherent interfacial properties (surface tension and wetting angle) determine the extent of liquid spreading on concrete and asphalt. As described in the second chapter, this spreading takes place in two phases. First, there is a rapid spreading as the liquid spreads out. Second, a creeping phenomenon takes place where the liquid follows the pull of gravity and slowly moves downhill. Both phases are the result of a balance of interfacial forces into a quasi-stable equilibrium. Knowledge of these properties allows one to determine the spill area on a flat, nearly impermeable surface.

The spreading area in the second case is mainly controlled by liquid viscosity and substrate permeability. How far a spilled liquid spreads over a porous substrate depends on how rapidly the liquid can flow over the surface before being entirely infiltrated. The dynamics of the flow over a porous surface determines the final spreading area for the viscosity-controlled second case.

In both situations, the initial liquid flow can be viewed as a "gravity current." For a gravity current, the spreading is controlled by the release rate of the spill and by the liquid's resistance to flow as characterized by its viscosity. This subject was discussed in a prior report (Simmons and Keller 2003).

This report will look at the simpler situation, spills on pavements, such as asphalt or concrete. While the surface is impermeable, there is surface roughness that will catch and hold the liquid as it flows and comes to an equilibrium. 


\subsection{Equations Regulating Spills on Pavements}

We will start with the simplest case of spills on an impermeable surface such as asphalt or concrete. Pavement provides a clear view of the spill. The identification of spills at a motor pool or airport is a real problem of concern. In this analysis, we make two simplifying assumptions:

1. We assume that all spills remain within the visible pavement area. The spill volume that runs off the pavement edges and into porous ground can not be estimated without ancillary information.

2. The effect of evaporation or other degradation of the material (Fate \& Transport) is negligible so that a final static distribution can be reached. This method does not apply to highly volatile liquids (which are better detected as gas-phase molecules).

When a spill happens on a relatively impermeable substrate, the force balance between the downward pull of gravity caused by the liquid's density and the internal tension of the liquid may allow the liquid pool or puddle to form a final size. Whether a final finite size is established depends on how strongly the liquid tends to adhere to the surface texture. In the model, the pool is thought of as being a large drop, with a defined amount of liquid held to a certain penetration depth in a slightly porous substrate. Some liquids, because of their adhesive property, may be capable of spreading nearly indefinitely to a molecular-size layer depth. In such cases, the extent of the pavement would limit the eventual spill size.

Depending on the adhesive property of the liquid, which is characterized by an effective contact angle of the pool edge with the surface pavement, the liquid will eventually stand a certain height or depth above the surface. The situation when the liquid has stopped spreading and has reached a quasi-static equilibrium is determinable.

Suppose volume V is spilled; then the volume partition over an area A is given by

$$
\mathrm{V}=\mathrm{A} \delta \phi+\mathrm{Ah}
$$

where $\mathrm{h}$ is the height of liquid standing above the surface. Liquid below the surface has penetrated to a certain depth, $\delta$, in the substrate porosity, $\phi$. The height is given by

$$
(1-\cos (\theta)) \cdot \sigma=\rho \cdot g \cdot h^{2}
$$

where $\mathrm{h}=$ spill height $(\mathrm{cm})$

$\rho=$ density $(\mathrm{gm} / \mathrm{ml})$

$\mathrm{g}=$ gravity acceleration

$\sigma=$ surface tension $($ dyne $/ \mathrm{cm})$

$\theta=$ contact angle

Figure 2.1 is a group of graphs that allow the liquid properties to be converted into an effective height. Table 2.1 provides physical properties for chemicals of interest. 


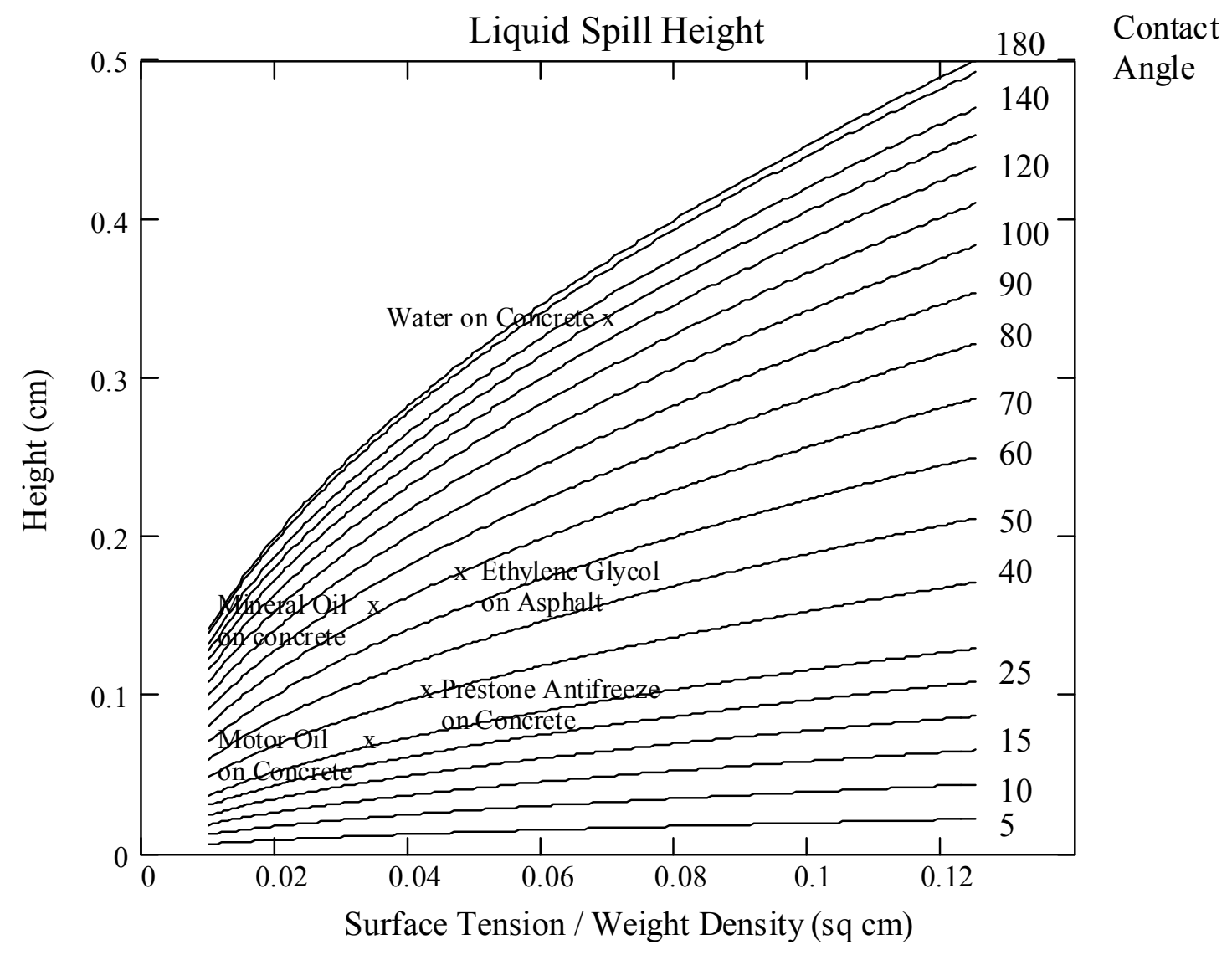

* Weight density $=\rho \cdot g$

Add wetting depth multiplied by porosity to obtain total effective height Spill volume equals area multiplied by effective spill height

Figure 2.1. Spill Height Model for Liquid with Contact Angle to Substrate. Height is determined by surface tension divided by weight density of the liquid for adhesion quantified by contact angle. 
Table 2.1. Physical Properties of Select Chemicals of Interest. $\sigma / \rho g$, with g equal to gravitational acceleration, corresponds to values along the $\mathrm{x}$-axis in Figure 2.1. Properties were measured at temperatures ranging from 20 to $25^{\circ} \mathrm{C}$ unless otherwise noted.

\begin{tabular}{|c|c|c|c|c|c|}
\hline Chemical & $\begin{array}{c}\text { Bulk } \\
\text { Density } \rho \\
\left(\mathbf{k g ~ m}^{-3}\right)\end{array}$ & $\begin{array}{c}\text { Surface } \\
\text { Tension } \sigma \\
\left(\text { dyne } \mathrm{cm}^{-1}\right)\end{array}$ & $\begin{array}{l}\text { Viscosity } \mu \\
\text { (centipoise) }\end{array}$ & $\begin{array}{l}\sigma / \mathbf{p g} \\
\left(\mathrm{cm}^{2}\right)\end{array}$ & Reference \\
\hline Water & 1000 & 72.0 & 0.98 & 0.0734 & USDC 1989 \\
\hline Ethylene Glycol & 1110 & 47.8 & 1.99 & 0.0439 & Hall and Hoff 2002 \\
\hline Ethanol & 787 & 21.8 & 1.07 & 0.0282 & Hall and Hoff 2002 \\
\hline n-Decane & 727 & 24.9 & 0.91 & 0.0349 & USDC 1989 \\
\hline Toulene & 861 & 28.5 & 0.59 & 0.0338 & USDC 1989 \\
\hline p-Xylene & 855 & 28.4 & 0.60 & 0.0339 & USDC 1989 \\
\hline Benzene & 877 & 28.9 & 0.65 & 0.0336 & USDC 1989 \\
\hline Trichloroethylene & 1458 & 28.7 & 0.55 & 0.0201 & Yaws 1999 \\
\hline Carbon Tetrachloride & 1599 & 28.2 & 1.05 & 0.0180 & USDC 1908 \\
\hline Mineral Oil & 860 & 30.9 & 47.9 & 0.0324 & McBride et al. 1992 \\
\hline Motor Oil (Used) ${ }^{(a)}$ & 885 & 31.0 & 175 & 0.0357 & CHRIS \\
\hline Gasoline & 731 & 20.5 & 0.48 & 0.0286 & USDC 1989 \\
\hline
\end{tabular}

Equation 2 was essentially derived by Adamson and Ling (1964) in an early discussion about the relationship between the thermodynamic aspects of adhesion and the Young-Dupre equation for defining the contact angle. In the original derivation, however, a factor of two multiplies the surface tension. By deriving this equation again, with a slightly different rationale of equating surface-energy change to change in gravitational potential energy, the two factor is cancelled out. The resulting equation also seems to be more consistent with a special case (Burdon 1949) originally used to estimate surface tension from the size of a small drop resting on a non-wetted surface. This is the situation for the non-wetting case when the contact angle is nearly 180 degrees. Zisman (1964) has also given a foundational discussion about the relationship between contact angle and the adhesion of various organic liquids to certain solid surfaces. Later, de Gennes (1985) again reviewed the subject of solid-surface wetting by a liquid. De Gennes treated more of the dynamic aspects of liquid spreading than considered in the earlier studies of adhesion. At this juncture, it seems apparent that an understanding of the complex adhesive 
interaction between various liquids and physically rough surfaces is at the crux of treating the problem of liquid spreading.

Surface tension tends to draw the liquid up into a shape of minimum surface energy, whereas gravity flattens the liquid mass against the surface. Equation 2 defines $h$ as a balance between these two opposing forces. Notice that a liquid that spreads entirely over the surface has a contact angle equal to zero: then $\mathrm{h}$ equals zero, and the spill volume is entirely subsumed into the surface roughness. Figure 2.2 provides a schematic describing contact-angle phenomena. The contact angle is measured between the surface and a tangent to the upper liquid surface through the contact edge. The contact edge exists at the three-phase meeting of liquid, solid, and air (including the vapor of the liquid). The contact angle can range between zero and 180 degrees. Liquids with a contact angle more than 90 degrees are said to be non-wetting on the substrate. Clearly, by Figure 2.1, liquids that wet the surface least will have greater height or pool depth.

In most situations, the surface is not absolutely flat and level, and then the contact angle is at best an apparent quantity representing an average value over the edge of a spill. The important physical principle applied here is that the liquid height is entirely independent of the area covered, and it has reached a final static distribution. This last condition is problematic because most liquids that adhere continue to exhibit a creeping, or spreading, phenomenon when any surface texture is present, especially if the surface is not absolutely level. Creeping is likely caused by capillary action within the surface groves/texture of the surface and tends to go in the direction of any local downhill slope. On the other hand, the capillary action is still associated with the likely unknown contact angle characterizing the adhesion of liquid to solid.

Note that the range of surface tension divided by weight density in Figure 2.1 is based on density being between 0.6 and 1.6 grams $/ \mathrm{ml}$ and surface tensions between 15 and 72 dyne/cm. Few liquids have property values outside this range. The formula, however, can be used directly to calculate effective height for liquids that might fall outside the graph range.
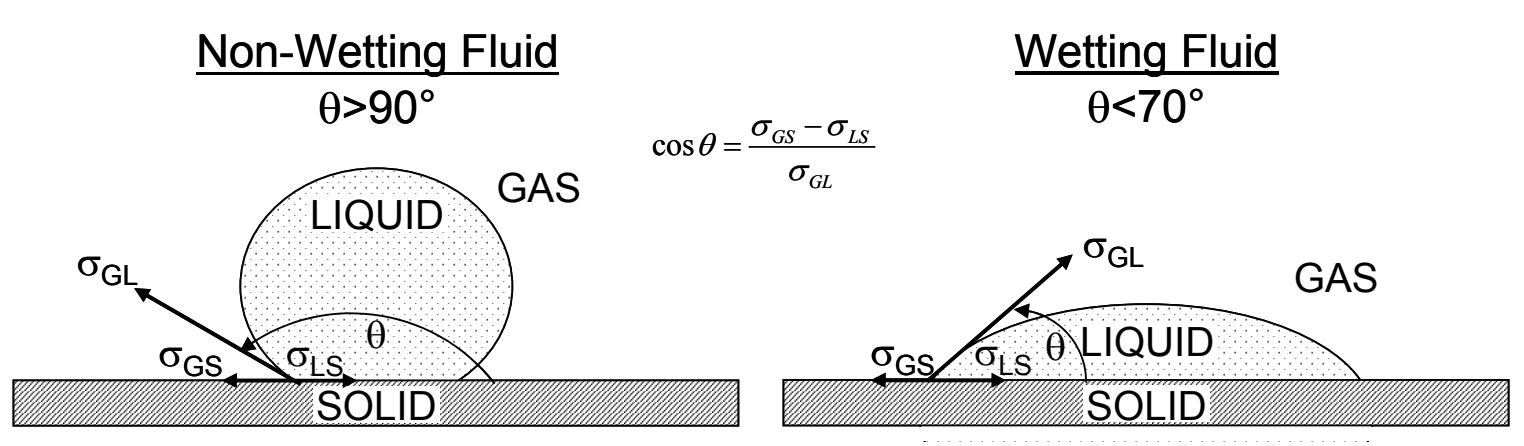

Figure 2.2. Contact-Angle Phenomena for Both Non-Wetting and Wetting Fluids. $\sigma_{\mathrm{GL}}$ is the interfacial tension between gas and liquid, $\sigma_{\mathrm{GS}}$ is the interfacial tension between gas and solid, and $\sigma_{\mathrm{LS}}$ is the interfacial tension between liquid and solid. Young's equation describing contact angle is also shown. 


\subsection{Experimental Spill Size Verification}

The theory for spill size determined by surface tension and adhesion, expressed by contact angle, was tested for a cement pavement with a few common liquids. A standard volume of $40 \mathrm{ml}$ of liquid was poured slowly during a few seconds onto a smooth level concrete floor. Some (low volatility) liquids used were water, antifreeze with water, antifreeze, $30 \mathrm{~W}$ motor oil, brake fluid, and mineral oil. Water and mineral oil are liquids with sufficiently known properties to judge the accuracy of the theory.

Following a spill of liquid when the liquid movement appeared to have come to rest, the area of spreading was traced on a transparent plastic sheet held above the area. The trace was transferred onto graph paper to estimate the area. The temperature of the concrete was relatively cold (Winter season) at about $40^{\circ} \mathrm{F}$ so that oils would be more viscous than in their typical range of use.

Figure 3.1 shows a spill of mineral oil, which is clear and transparent like water. Its surface reflected the camera flash, and hairline fractures are clearly visible in the concrete surface. The picture was taken at a stage in puddle-distribution development when the creeping spread was just underway. The outline of the spill at two times is shown in Figure 3.2. The smaller spot was taken when the outward initial spreading appeared to come to rest, before creeping began.

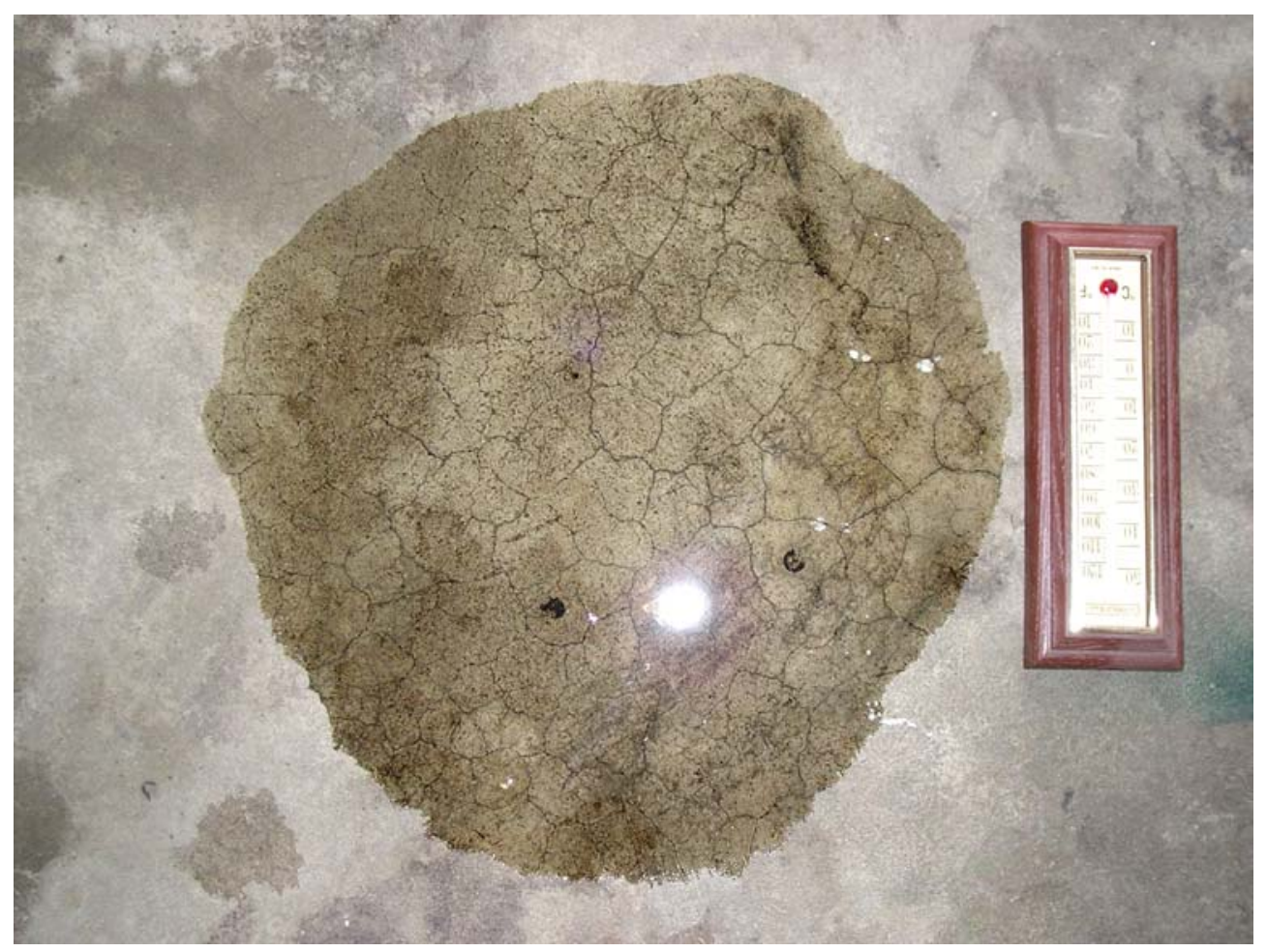

Figure 3.1. Picture of Mineral Oil Spot on Smooth Concrete Floor. (Oil Volume is $40 \mathrm{ml}$.). Thermometer shown is $16.2-\mathrm{cm}$ long, and red bulb is pointed down slope. Creeping spread has begun about an hour after the spill. 


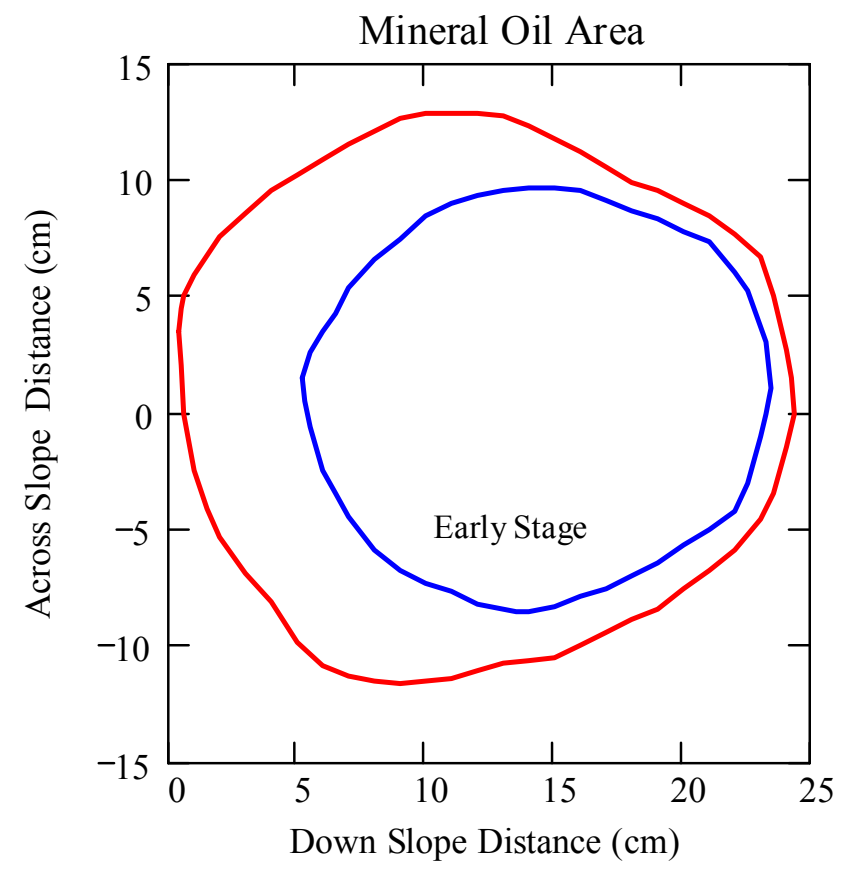

Red Curve corresponds to spill picture in Figure (3) about $1 \mathrm{hr}$ after spill. Blue curve corresponds to quasi-equilibrium of same spill after initial flow.

Figure 3.2. Outline of Mineral Oil Spill Area. Inner area (blue) is 250 sq. cm, whereas larger area (red) is 445 sq. $\mathrm{cm}$. The larger area corresponds to the size of the spot about 1 hour after creeping has started.

A contact angle for mineral oil was calculated using the earliest or smallest area of Figure 3.2. Mineral oil has a density of about $0.86 \mathrm{gm} / \mathrm{ml}$ and surface tension of $31 \mathrm{dyne} / \mathrm{cm}$. The earliest area yields a contact angle of 72.3 degrees, whereas the larger gives 38.7 degrees. The height of the earlier area is $0.16 \mathrm{~cm}$ and $0.09 \mathrm{~cm}$ for the larger. These estimates presume a minor absorption of oil in the concrete. McBride et al. (1992) reported a dynamic contact angle of 72.5 degrees for mineral oil imbibed into a moist porous medium by capillary rise.

A similar test was done for water and motor oil for comparison. Water has a density about $1 \mathrm{gm} / \mathrm{ml}$ and surface tension 72 dynes $/ \mathrm{cm}$. This gives a contact angle of 125 degrees for water, a value within the typical range for surfaces on which water is non-wetting. The concrete is suspected of being somewhat hydrophobic because of possible exposure to organic automobile fluids (i.e., oil). The water puddle remained static in final shape over an hour or two, while the motor oil continued to spread. Although the exact properties of the motor oil are not available, the oil is considerably more viscous (similar to mineral oil with about 50 centipoise) than water, yet the oil spread considerably more in about the same time. The height of the final water puddle is $0.34 \mathrm{~cm}$ and only $0.068 \mathrm{~cm}$ for motor oil. Possibly the motor oil is a complete wetting liquid, with nearly zero contact angle, but would require substantially longer to continue toward a static final distribution given the high viscosity limiting its spreading rate. A gravity-current estimation is needed to determine if the oil spreading was mainly being driven by adhesion or simply by collapse of height under its own weight. The outline of the motor oil spill and water spill are shown in Figure 3.3. 


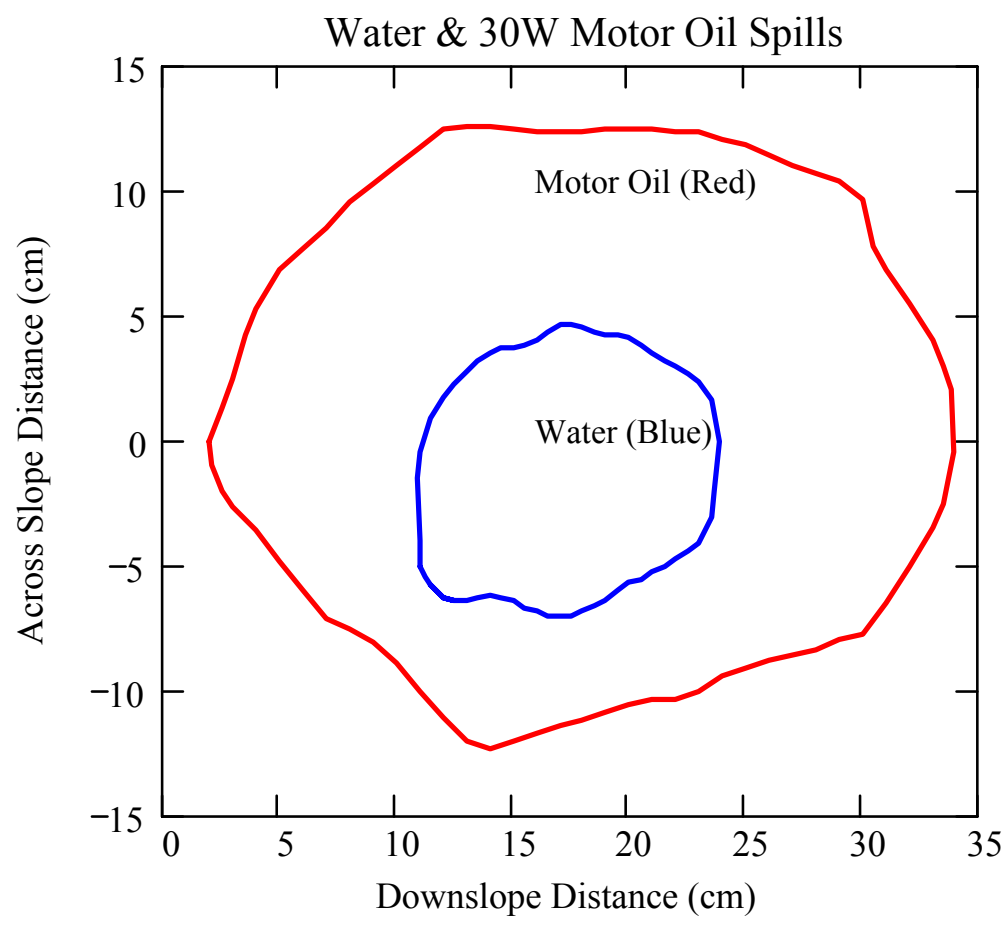

Figure 3.3. Water and Motor Oil Spill Puddles. Spill volume is $40 \mathrm{ml}$. Areas are 118 and $585 \mathrm{sq} . \mathrm{cm}$ for water and oil, respectively. (Note that actual spill test areas were not nested as shown. Different locations on the concrete were used.) Using Equation 2, it is possible to determine the contact angle for water $\left(125^{\circ}\right)$ on concrete. The properties of motor oil are not well enough defined to determine the contact angle.

A regular or symmetrical pattern of spreading is the ideal case for a perfectly flat and smooth surface. In general, slight imperfections in tilt or surface texture can cause a smoothly flowing liquid to follow essentially unpredictable spreading. For instance, if the concrete surface is wet with water rather than dry, mineral oil will spread differently, as contrasted in Figure 3.4. The behavior stems from the mineral oil's tendency to not wet (adhere) to a water surface. The slightest surface tilt then propels the liquid downhill. 


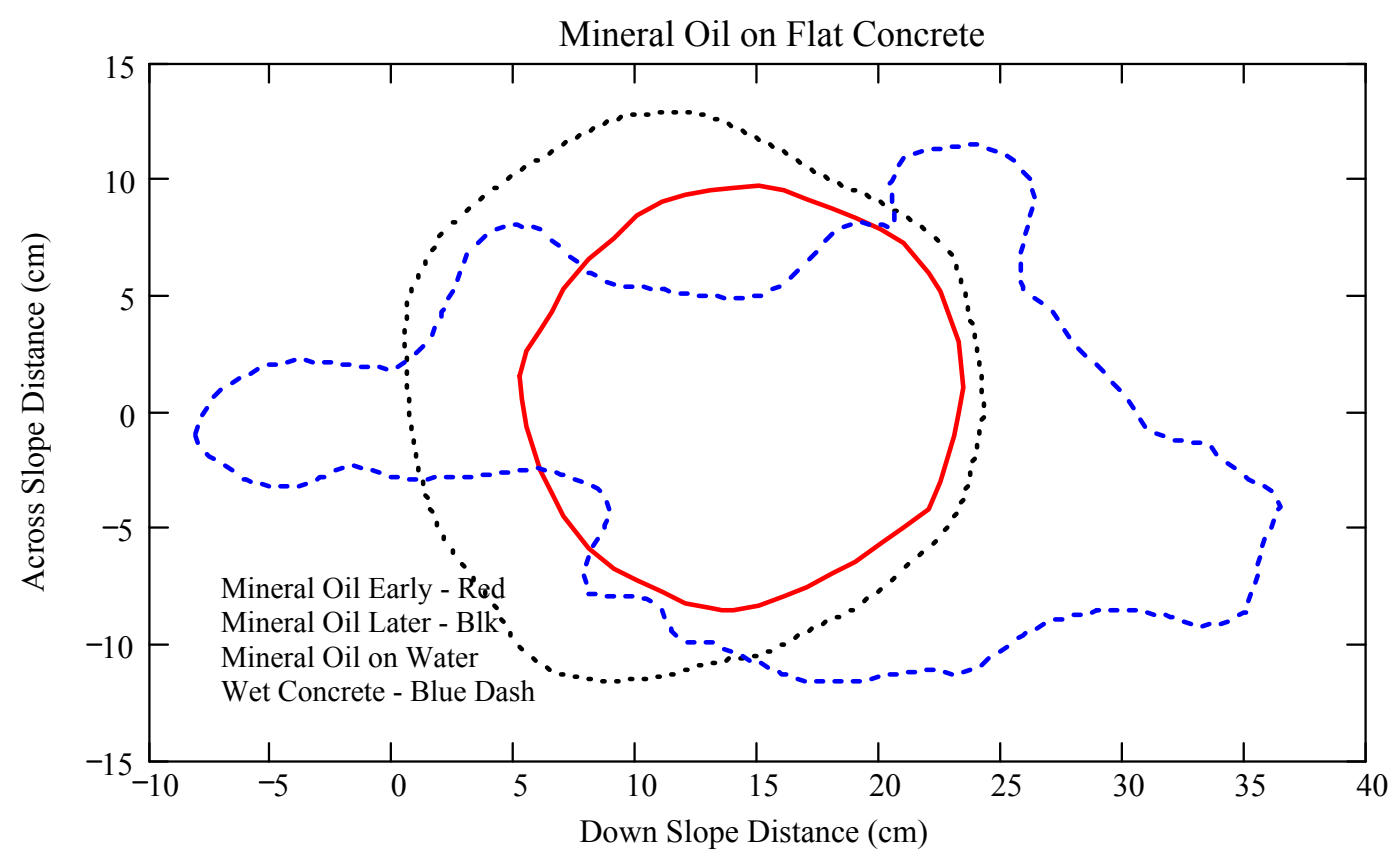

Figure 3.4. Mineral Oil Spreading on Dry and Wet Concrete. Coordinate origin is arbitrary, and spills were not applied to the same surface area - not overlapping as shown. The distance scale extends to negative values when the spreading area could not be fit on a standard size sheet of graphing paper. See Table 3.1 for areas. The dot areas were taken after about an hour. Across distance is transverse.

A summary of estimated liquid depths and contact angles is provided in Table 3.1. Contact angles are apparent and average values. These values could be computed only if values for surface tension and density where available. For instance, the surface tension of motor oil is not known to calculate contact angle. It is presumed that a negligible liquid amount absorbed into the concrete (an effort was made to check this later).

Table 3.1. Sizes of Liquid Spills on Concrete Floor. Spill volume is $40 \mathrm{ml}$ in all cases.

\begin{tabular}{|c|c|c|c|}
\hline Liquid on Concrete & $\begin{array}{c}\text { Surface } \\
\text { Area }\left(\mathrm{cm}^{2}\right)\end{array}$ & $\begin{array}{l}\text { Liquid Height h } \\
\text { (cm) }\end{array}$ & $\begin{array}{c}\text { Contact Angle } \\
\theta\left({ }^{\circ}\right)\end{array}$ \\
\hline Water & 117.5 & 0.340 & 125 \\
\hline Motor Oil 30W & 585 & 0.068 & -- \\
\hline Prestone Antifreeze & 384 & 0.104 & 42 \\
\hline Brake Fluid DOT 3 & 840 & 0.048 & $\overline{--}$ \\
\hline Mineral Oil & 250 & 0.160 & 72.3 \\
\hline Mineral Oil on Wet & 515 & 0.078 & 33.3 \\
\hline Mineral Oil Later & 445 & 0.090 & 38.7 \\
\hline
\end{tabular}


Brake fluid exhibited a tendency to spread very rapidly and seek slight down-slope channels. Apparently, the wetting of brake fluid on concrete is quite different than mineral oil. In particular, brake fluid is a much less viscous liquid than oil as well.

Figure 3.5 is a summary of liquid spots produced by the verification tests. Note the two fingers of continuing down-slope movement developed by the brake fluid. It is expected that the fluid would continue moving as liquid gathers and deepens at the ends of the advancing fingers. A spill involving water-diluted antifreeze (not shown) produced a smaller spot than antifreeze, consistent with the fact that the mixture would likely exhibit somewhat more the properties of water (greater surface tension and lower viscosity). The antifreeze is identified as mainly ethylene glycol, having a surface tension of $47.7 \mathrm{dyne} / \mathrm{cm}$ and a density of $1.13 \mathrm{~g} / \mathrm{ml}$, including partly diethylene glycol. The pure antifreeze was clearly much more viscous than water and slower flowing when poured.

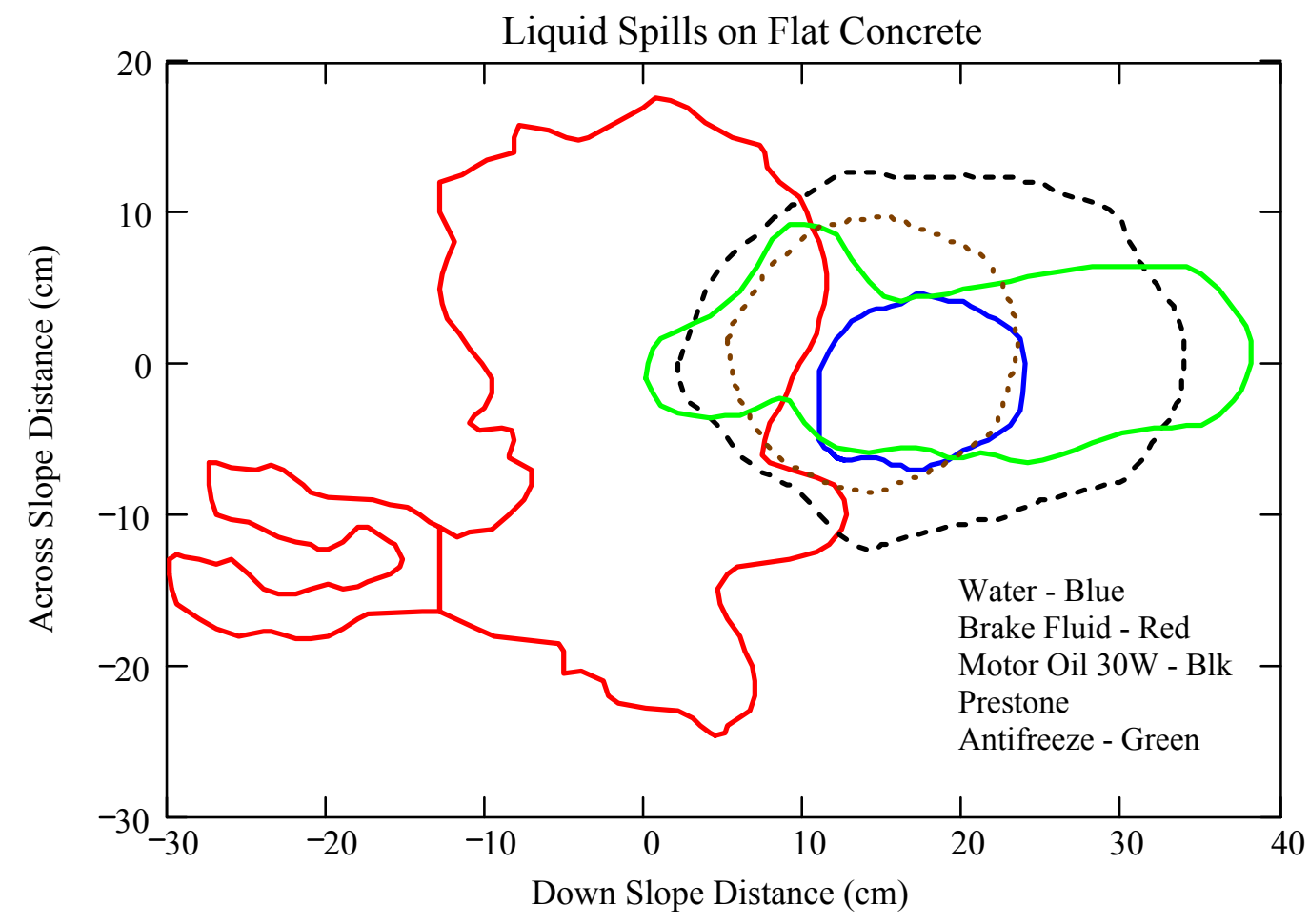

Figure 3.5. Spilled Liquid Areas. The mineral oil spot is indicated by a brown dot curve corresponding to Figure 3.4. No spills were applied to the same actual surface area as displayed for comparison. Across distance means transverse to slope. The zero is arbitrary, but the down slope goes to lower numbers.

The presumption of the spreading model is that the liquid height would apply regardless of the actual spilled volume. Thus, liquid height given in Table 3.1 is a conversion factor from area to volume regardless of spill amount, provided the spill volume remains on the pavement. 
Finally, it is pointed out that the creeping form of spreading that continues as the wetting contact is continually changed by exposure of the surface to the liquid is a model-prediction challenge. In other words, no simple model is available presently to predict the final outcome. Figure 3.6 shows a picture of the eventual spreading that occurred in about a day and a half for mineral oil. Apparently, the static equilibrium condition used to estimate contact angle was only a transitory situation. In other words, the nature of the actual substrate surface eventually did not allow for an ideal equilibrium to be established. In a day and a half, the spot grew to an area of $1370 \mathrm{~cm}^{2}$.

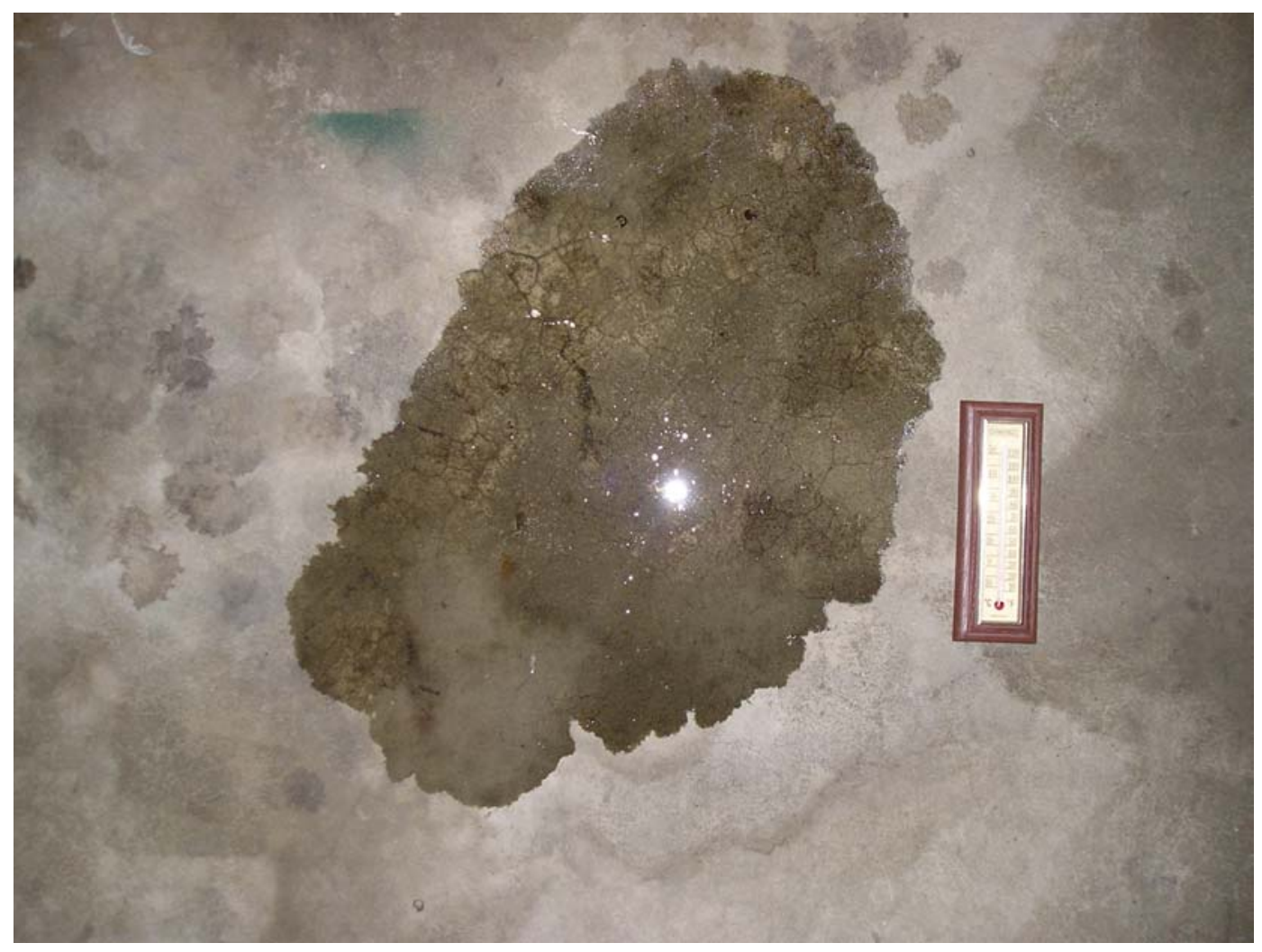

Figure 3.6. Mineral Oil Spill after Continued Spreading. Spot $(40 \mathrm{ml})$ after one and a half days. Thermometer is $5.6 \mathrm{~cm} \times 16.2 \mathrm{~cm}$. Down slope end is toward the red bulb.

The mineral oil spot in Figure 3.6 shows small finger protrusions from the edge where the liquid is advancing outward. Apparently, the concrete had fine groves that the liquid is moving along down slope until the liquid again merges across these groves. The liquid height at the down slope end is greater than at the end where the spill began (see Figure 3.1). This difference in height from the down slope leading edge to the trailing edge reflects an increase in the contact angle at the advancing front and a decrease in the angle at the receding end. This is a general principle for the spreading phenomenon. The advancing contact angle must be greater to balance the greater liquid height at the front according to the equilibrium viewpoint of Equation 2. Equation 2 can be thought to hold at each location around the liquid spot's edge. The contact angle is then an apparent value relative to the horizontal plane. 


\subsection{Spill Simulations}

Simulations of hypothetical spills on ideal asphalt and concrete surfaces were performed to determine the final areal extent of the spill and its relation to spill rate and spill quantity. In addition, the effect of surface slope on spill area, spill shape, and the time progression of the spill were evaluated. The simulations were performed using the liquid pool equilibrium model presented earlier along with a 2-D gravity current depiction of overland flow coupled with the Green-Ampt infiltration model described in Appendix A.

\subsection{Substrate Considerations}

In considering an ideal substrate, we assume that tilt and surface texture remain homogeneous throughout the domain being considered and the substrate surface is completely dry before the spill. Properties of the asphalt and concrete surfaces considered in the simulations are presented in Table 4.1.

Table 4.1. Substrate Properties

\begin{tabular}{|l|c|c|c|l|l||}
\hline Substrate & $\begin{array}{c}\text { Bulk } \\
\text { Density } \rho \\
\left(\mathbf{g ~ c m}^{-3}\right)\end{array}$ & $\begin{array}{c}\text { Porosity } \phi \\
\left(\mathbf{c m}^{\mathbf{3}} \mathbf{c m}^{-3}\right)\end{array}$ & $\begin{array}{c}\text { Intrinsic } \\
\text { Permeability k } \\
\left(\mathbf{c m}^{\mathbf{2}}\right)\end{array}$ & Notes & Reference \\
\hline Asphalt & -- & 0.09 & $10^{-8}$ & $\begin{array}{l}\text { Florida Department of } \\
\text { Transportation maximum } \\
\text { allowable intrinsic } \\
\text { permeability }\end{array}$ & Maupin 2000 \\
\hline Concrete & 2.07 & 0.16 & $10^{-13}$ & $1: 3$ cement & Hall and Hoff 2002 \\
\hline
\end{tabular}

While highly impermeable, asphalt and concrete surfaces generally possess a surface roughness in the form of small surface depressions. These depressions act to store liquid, effectively removing the liquid from the surface flow (Figure 4.1). To account for such surface roughness in the simulations, a storage depth $(\delta)$ may be set to account for the idealized depressions. As presented by the American Concrete Pavement Association (http://www.pavement.com), surface texturing of concrete produces striations that vary from $1.5 \mathrm{~mm}$ to $6 \mathrm{~mm}$ in depth, depending on the texturing method. While $\delta$ would generally vary for differing impermeable substrates, a value of $2 \mathrm{~mm}$ is believed to be representative for the asphalt and concrete substrates considered in this report. 


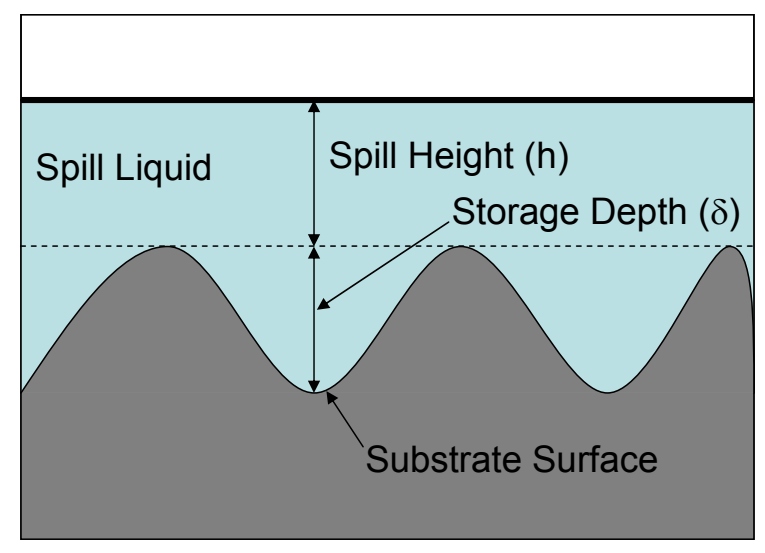

Figure 4.1. Model Representation of Surface Roughness

As described previously, spills on an impermeable surface will eventually cease to spread, at which point the pool is said to have reached a quasi-static equilibrium between the downward pull of gravity and the internal tension of the liquid. At such time, the pool will stand a certain height (h) as determined by the adhesive properties of the spilled liquid and calculated using Equation 2. Because gravity-current theory used in the spill model describes overland flow as continuing until the spill height has reached some infinitesimal value, prior knowledge of $h$ is needed to determine when the pool has reached quasi-static equilibrium and the simulation is complete.

Using Equation 2, h was calculated for each liquid spill scenario simulated herein. During the simulations, the average height of the spilled liquid was calculated at each time step. Once the average height of the liquid was equal to $h$, the simulation was terminated. Table 4.2 lists the pertinent physical properties of the liquids used in the spill simulations as well as the substrate-specific calculated $\mathrm{h}$.

Table 4.2. Physical Properties of Spilled Liquids. "h" is calculated using Equation 2. Where not stated, references for property values can be found in Table 2.1.

\begin{tabular}{|c|c|c|c|c|c|c|c|}
\hline \multirow[b]{2}{*}{ Liquid } & \multirow{2}{*}{$\begin{array}{c}\text { Density } \rho \\
\left(\mathrm{kg} \mathrm{m}^{-3}\right)\end{array}$} & \multirow{2}{*}{$\begin{array}{c}\text { Surface Tension } \sigma \\
\left(\text { dyne } \mathrm{cm}^{-1}\right)\end{array}$} & \multirow{2}{*}{$\begin{array}{l}\text { Viscosity } \mu \\
\text { (centipoise) }\end{array}$} & \multicolumn{2}{|c|}{$\begin{array}{c}\text { Contact Angle } \theta \\
\left({ }^{\circ}\right)\end{array}$} & \multicolumn{2}{|c|}{$\begin{array}{c}\text { Equilibrium Spill } \\
\text { Height h (mm) }\end{array}$} \\
\hline & & & & Asphalt & Concrete & Asphalt & Concrete \\
\hline Water & 1000 & 72.0 & 0.98 & $95^{(\mathrm{a})}$ & $125^{(\mathrm{b})}$ & 2.8 & 3.4 \\
\hline Ethylene Glycol & 1110 & 47.8 & 1.99 & $70^{(a)}$ & -- & 1.7 & -- \\
\hline Mineral Oil & 860 & 30.9 & 47.9 & -- & $72.3^{(\mathrm{b})}$ & -- & 1.5 \\
\hline \multicolumn{8}{|c|}{$\begin{array}{l}\text { (a) Drelich and Miller } 1994 . \\
\text { (b) Measured. }\end{array}$} \\
\hline
\end{tabular}


Before executing the run of simulations, a preliminary model validation was performed to ensure that the model was functioning properly. Validation was done by simulating the experimental spill of mineral oil presented in the previous section and comparing the computed spill area and spill shape at static equilibrium to that observed experimentally. The release of the $40 \mathrm{ml}$ of mineral oil was simulated as occurring over a one-second interval onto a concrete surface sloped one degree. A storage depth $(\delta)$ of $2 \mathrm{~mm}$ was used, and $\mathrm{h}$ was calculated using the experimentally obtained contact angle $(\theta)$, as presented in Table 4.2. Figure 4.2 displays the spatial extent of the simulated spill overlaid by the perimeter of the experimental spill. The coverage of the simulated spill is comparable to that observed, with the simulated spill area being more symmetrical than the observed area. Slight elongation of the observed spill in the transverse direction is observed, possibly due to a slight slope or surface irregularity in that direction. The coverage of the simulated spill is nearly identical to that observed, with the simulated spill area and observed area being $270 \mathrm{~cm}^{2}$ and $250 \mathrm{~cm}^{2}$, respectively. Cracks that were present in the cement may have led to the slight overestimate of spill area by acting as a sink for the spilled liquid.

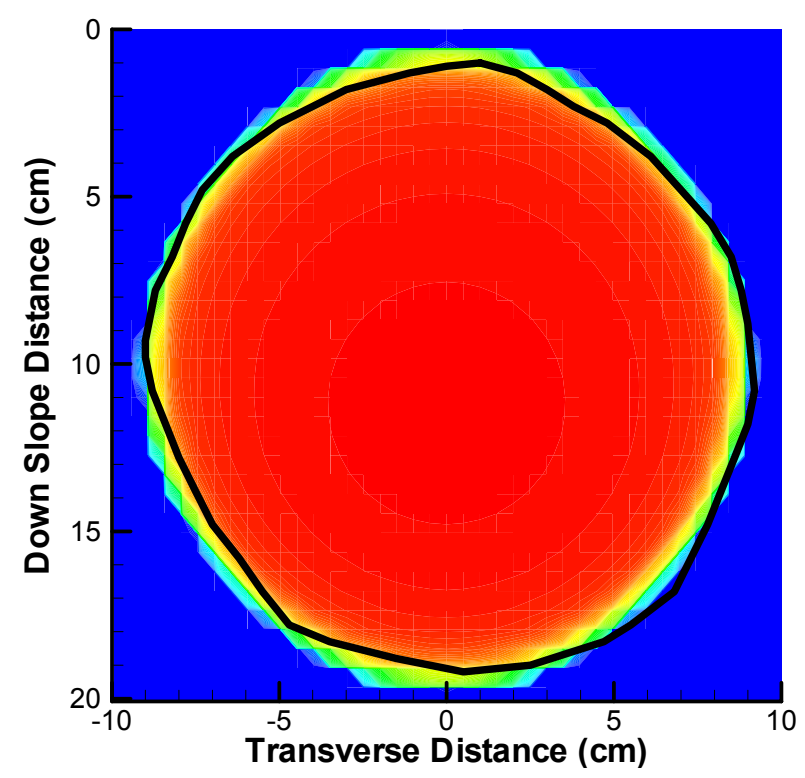

Figure 4.2. Spatial Extent of Simulated $40 \mathrm{Ml}$ Mineral Oil Spill (Red) and Observed Coverage from Experiment (Black Line)

While the preliminary model validation demonstrates that under the above spill conditions the model functions well, a more robust model validation consisting of additional comparisons between simulated and experimental results using an assortment of liquids and substrates is needed. This validation would allow for increased assurance of model accuracy and performance.

To explore the effect of spill quantity and spill rate on the size of the spill area, simulations were performed consisting of spills of water or ethylene glycol on a one-degree sloped asphalt surface and spills of water or mineral oil on a one-degree sloped concrete surface. All spills were simulated at spill rates of $0.5 \mathrm{gal} / \mathrm{sec}, 5 \mathrm{gal} / \mathrm{sec}$, and $55 \mathrm{gal} / \mathrm{sec}$. Simulations were run until the average pool height equaled the equilibrium spill height presented in Table 4.2. Simulation results are presented in Figure 4.3. For all 

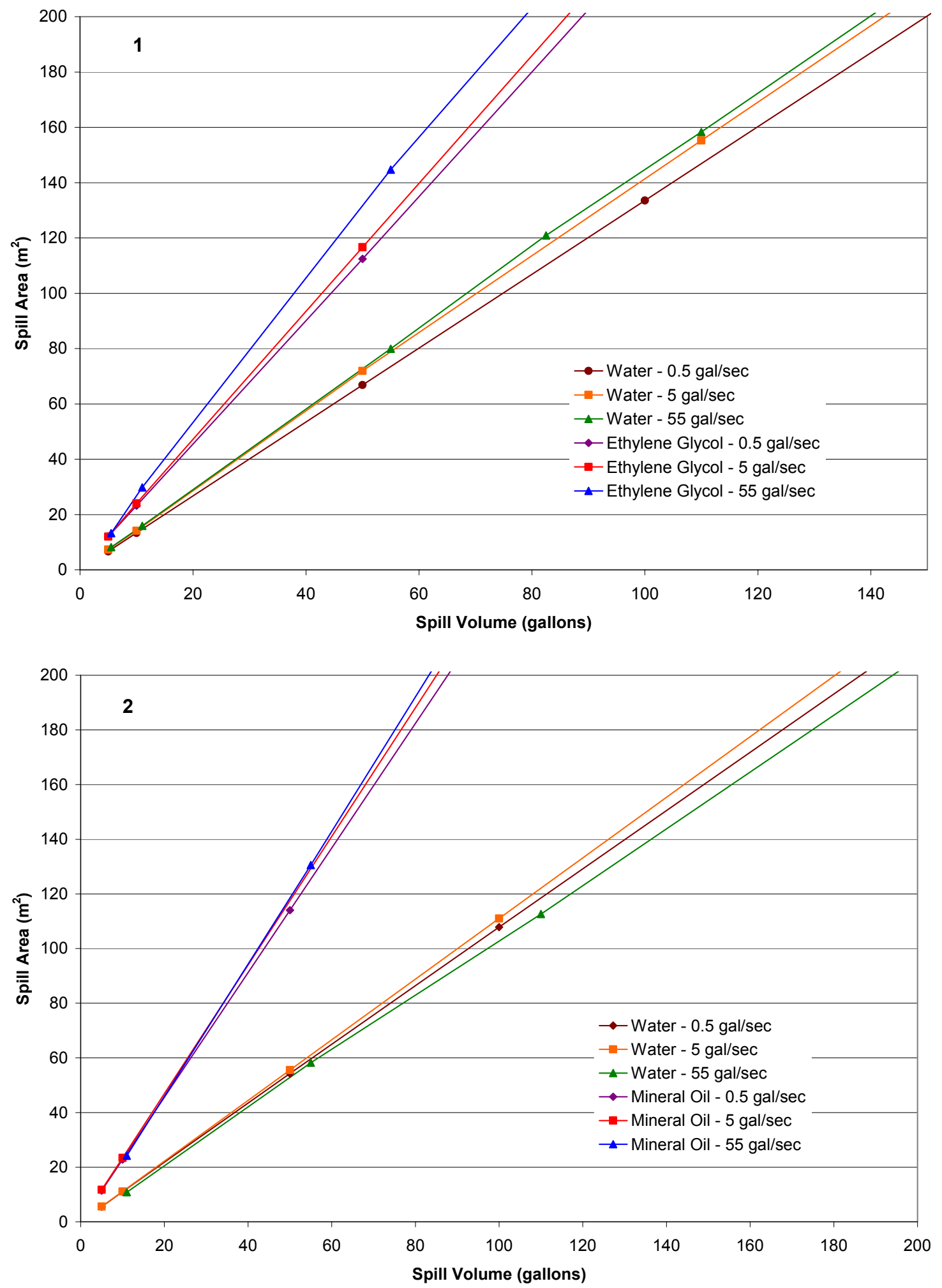

Figure 4.3. Spill Area as a Function of Total Spill Volume for 1) an Asphalt Surface at a One-Degree Slope and 2) a Concrete Surface at a One-Degree Slope 
spill scenarios, a linear relationship is observed between spill volume and spill area. From Equation 1, this relationship is expected on an impermeable surface and again verifies that the model is functioning correctly. The wetting liquids (i.e., ethylene glycol and mineral oil) had greater area coverage than the nonwetting liquid (i.e., water). This expected result is because the wetting liquids have smaller equilibrium spill heights than those of the nonwetting liquids, resulting in greater spreading before the pool reaches static equilibrium.

Adjustment of spill rate had little effect on the final area of the spill. The spill rate did have a notable effect on the time progression of the spill. As an example, the simulated release of 110 gal of water on asphalt took 15 seconds for the 5 -gal/sec spill to reach static equilibrium, as opposed to 5 seconds taken by the $55-\mathrm{gal} / \mathrm{sec}$ spill.

Next, a series of simulated 55-gal mineral-oil spills on concrete were run with slopes ranging from zero to five degrees. Figure 4.4 shows the spatial extent of the simulated spills as they relate to slope. Table 4.3 displays the spill area at static equilibrium for each slope and the elapsed time required for the simulation to reach static equilibrium. The slope had no effect on the computed spill area, with all spills resulting in similar if not identical spill areas. The spill shape did change significantly as the slope increased, becoming more elongated with slope. The spill on a zero-degree slope resulted in a radial spill area of approximate dimensions $10 \mathrm{~m}$ by $10 \mathrm{~m}$. In contrast, the spill on the five-degree slope produced a highly elongated spill area with an approximate maximum dimension of $32 \mathrm{~m}$ long and $4 \mathrm{~m}$ wide. Increasing the slope also increased the rate of spill development with the one-degree slope reaching equilibrium in 599 seconds while the spill on the flat plane required 3513 seconds, illustrating the significance of slope in overland flow dynamics.

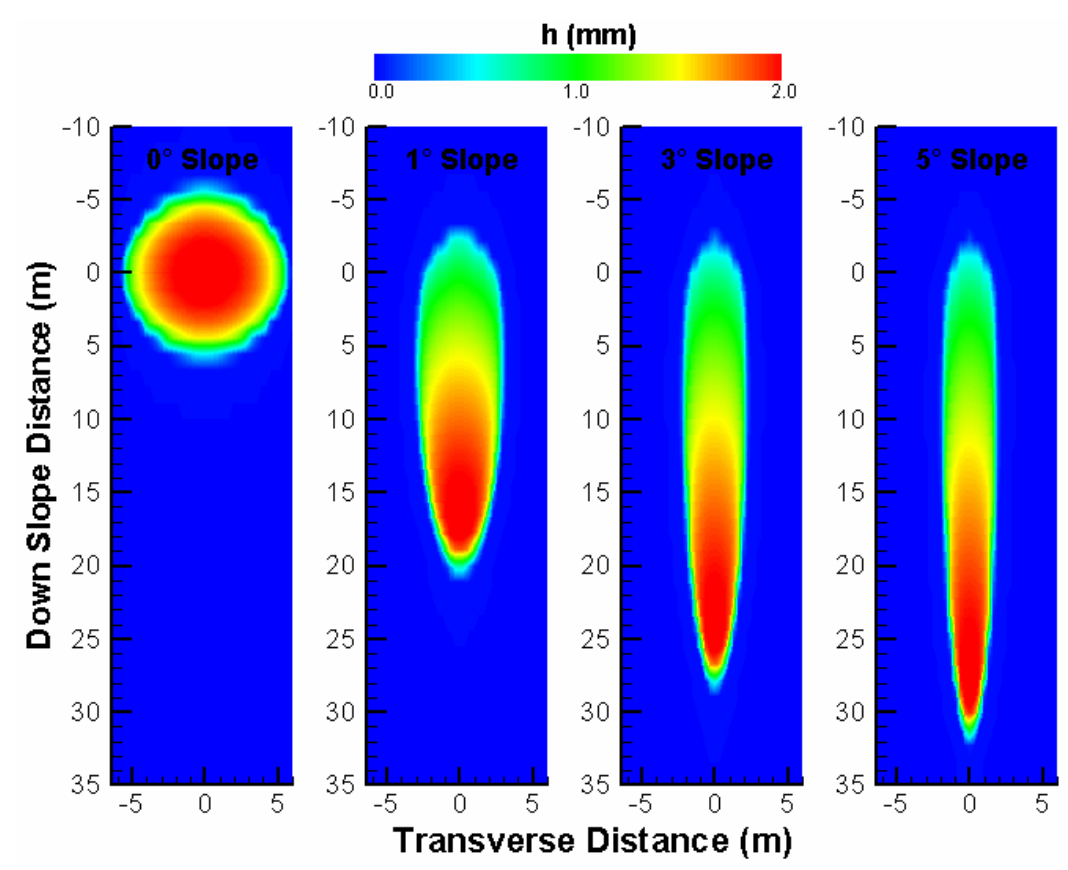

Figure 4.4. Simulated Mineral Oil Spill Spatial Extent as a Function of Slope. "h" equals liquid pool height. 
Table 4.3. Simulated Spill Area and Spreading Time for a Mineral Oil Spill on Varying Slopes

\begin{tabular}{||c|c|c||}
\hline $\begin{array}{c}\text { Slope } \\
\left(\mathbf{(}^{\circ}\right.\end{array}$ & $\begin{array}{c}\text { Spill Area at } \\
\text { Static } \\
\text { Equilibrium }\left(\mathbf{m}^{\mathbf{2}}\right)\end{array}$ & $\begin{array}{c}\text { Time to Reach Static } \\
\text { Equilibrium (sec) }\end{array}$ \\
\hline 0 & 134.2 & 3513 \\
\hline 1 & 138.8 & 599 \\
\hline 3 & 138.8 & 244 \\
\hline 5 & 138.8 & 163 \\
\hline
\end{tabular}

Finally, a set of simulated mineral oil spills was performed on a one-degree sloped concrete surface in which the spill was allowed to run off the down slope simulation domain. Such a scenario may represent an instance when a surface drain is located on the edge of the pavement. Fifty-five gallon spills were simulated at rates of $0.5 \mathrm{gal} / \mathrm{sec}, 5 \mathrm{gal} / \mathrm{sec}$, and $55 \mathrm{gal} / \mathrm{sec}$. The spills were allowed to run down slope for 2 meters before exiting the simulation domain. Table 4.4 presents the results of the simulations. A comparison of spill area against that presented in Table 4.3 shows that the loss of the spilled liquid results in a considerably reduced spill area, with spill area decreased by approximately 95 percent. In addition, the spill area decreased as the spill rate increased. This is expected as the larger spill rate results in an increased rate of down-slope spill movement.

Table 4.4. Simulated Spill Area and Spreading Time for a 55-Gal Mineral Oil Spill on a One-Degree Slope with Spilled Liquid Running off the Edge of the Simulated Domain

\begin{tabular}{|c|c|c||}
\hline $\begin{array}{c}\text { Spill Rate } \\
\left(\mathbf{g a l ~ s e c ~}^{-1}\right)\end{array}$ & $\begin{array}{c}\text { Spill Area at } \\
\text { Static } \\
\text { Equilibrium } \\
\left(\mathbf{m}^{\mathbf{2}}\right)\end{array}$ & $\begin{array}{c}\text { Time to } \\
\text { Reach Static } \\
\text { Equilibrium } \\
(\mathbf{s e c})\end{array}$ \\
\hline 0.5 & 11.9 & 63 \\
\hline 5 & 8.1 & 116 \\
\hline 55 & 5.0 & 194 \\
\hline
\end{tabular}

A significant aspect concerning spills on an impermeable surface is the importance of contact angle $(\theta)$ in the calculation of $\mathrm{h}$ from Equation 2. Because Equation 2 essentially determines the final spill area (i.e., when the pool has reached static equilibrium), accurate knowledge of $\theta$ is necessary to correctly calculate the final spill area. Table 4.5 presents the calculated final spill area for a 55-gal spill of mineral oil on concrete using the measured contact angle of 72.3 degrees and a range of additional contact angles. A 58-percent error in calculated spill area results when a contact angle of 45 degrees is used instead of the measured contact angle. This corresponds to a $0.05-\mathrm{mm}$ change in equilibrium surface height. The open literature contains an abundance of contact-angle data for pure liquids on inert homogeneous substrates such as Teflon and glass, but very little contact-angle data exists for liquids on materials composed of 
asphalt, concrete, or soil. This is especially true for mixtures such as coolant, brake fluid, and motor oil. This necessitates the need for measurements of contact angle for various fluids over different asphalt, concrete, and soil substrates.

Table 4.5. Calculated Equilibrium Spill Height and Spill Area Using the Measured $\left(72.3^{\circ}\right)$ Contact Angle for Mineral Oil on Concrete and Additional Contact Angles. Spill volume equals 55 gallons.

\begin{tabular}{|c|c|c|c||}
\hline $\begin{array}{c}\text { Contact } \\
\text { Angle } \boldsymbol{\theta}\left(\mathbf{(}^{\circ}\right)\end{array}$ & $\begin{array}{c}\text { Equilibrium } \\
\text { Spill Height } \\
\mathbf{h}(\mathbf{m m})\end{array}$ & $\begin{array}{c}\text { Spill Area at } \\
\left.\mathbf{h} \mathbf{( m}^{\mathbf{2}}\right)\end{array}$ & $\begin{array}{c}\text { Percent } \\
\text { Error } \mathbf{( \% )}\end{array}$ \\
\hline 72.3 & 0.15 & 138 & -- \\
\hline 45 & 0.10 & 218 & -58.0 \\
\hline 50 & 0.11 & 193 & -39.9 \\
\hline 55 & 0.12 & 176 & -27.5 \\
\hline 60 & 0.13 & 164 & -18.8 \\
\hline 65 & 0.14 & 158 & -14.5 \\
\hline 80 & 0.16 & 127 & 8.0 \\
\hline 85 & 0.17 & 121 & 12.3 \\
\hline 90 & 0.18 & 115 & 16.7 \\
\hline
\end{tabular}

As was done in Section 3, the contact angle can be indirectly measured by releasing a known volume of the liquid of interest onto the desired substrate and measuring the surface area of the liquid pool once it has reached static equilibrium. Using Equation 1, the measured area of the pool can be related to pool height (h), allowing Equation 2 to be solved for the contact angle, given that the density and surface tension of the liquid are known. An alternative method to determine contact angle is to use a semiempirical equation-of-state presented as ( $\mathrm{Li}$ and Neuman 1990)

$$
\cos \theta=2 \sqrt{\frac{\sigma_{S V}}{\sigma_{L V}}} e^{-\beta\left(\sigma_{L V}-\sigma_{S V}\right)^{2}}-1
$$

where $\sigma_{\mathrm{SV}}$ and $\sigma_{\mathrm{LV}}$ are the surface energy of a solid and the surface tension of a liquid, respectively, and $\beta$ is constant with a value of $0.0001247\left(\mathrm{~m}^{2} / \mathrm{mJ}\right)^{2}$. Complications exist with this method in that $\sigma_{\mathrm{SV}}$ is difficult to measure, and limited data exists in the open literature. In addition, Equation 3 has been shown to only be applicable to apolar systems (Drelich and Miller 1994). 


\subsection{Conclusion}

The extent that a liquid will flow over a nearly impermeable surface is determined by the inherent interfacial properties (surface tension and wetting angle) of the liquid. Knowledge of such properties allows determination of spill extent using the pool spreading equilibrium model presented in this report. Coupling of the spreading equilibrium model to the 2-D gravity current and Green-Ampt infiltration model (Appendix A) allows for spill progression and spill shape to be determined and provides the ability to consider surface roughness.

A variety of spill scenarios were simulated, and the model was successfully implemented. A linear relationship between spill area and spill volume was confirmed. The simulations showed that spill rate had little effect on the final spill area. Slope had an insignificant effect on the final spill area, but it did modify the spill shape considerably. However, a fluid sink on the edge of the simulation domain, representing a storm drain, resulted in a substantial decrease in spill area. A bona-fide effort to determine the accuracy of the model and its calculations remains, but comparison against observations from a simple experiment showed the model to correctly determine the spill area and general shape under the conditions considered. Further model verification in the form of comparison against small-scale spill experiments are needed to confirm the model's validity.

A literature search for contact angle $(\theta)$ values for liquid on asphalt, concrete, and soil has revealed that there is a lack of $\theta$ data for contact angle. Considering the importance of $\theta$ in determining the final extent of a spill on impermeable surfaces, the $\theta$ for various liquids on different substrates will likely have to be measured to obtain consequential results.

It is important to note that the simulations presented in this report represent spills on ideal surfaces in which surface texture and slope remain constant. Such conditions may significantly alter the final spill area and shape due to changing storage depths and channeling of the overland flow. Subsequent reports will consider such conditions.

Ensuing reports will also consider spills on permeable surfaces. With permeable surfaces, interfacial properties will be less important in controlling spill area while liquid viscosity and substrate permeability will largely influence the final spill extent. 


\subsection{References}

Adamson AW, and I Ling. 1964. "The Status of Contact Angle as a Thermodynamic Property." In Contact Angle, Wettibility, and Adhesion, ed. RF Gould, Advances in Chemistry Series 43, American Chemical Society, Washington, D.C.

Burdon RS. 1949. Surface Tension and the Spreading of Liquids. $2^{\text {nd }}$ edition. Cambridge University Press, London.

Drelich J, and JD Miller. 1994. "Examination of Neumann's Equation-of-State for Interfacial Tensions." Journal of Colloid and Interface Science 167:217-220.

Hall C, and WD Hoff. 2002. "Water Transport in Brick, Stone and Concrete." Spon Press, New York.

Hussein M, M Jin, and JW Weaver. 2002. "Development and Verification of a Screening Model for Surface Spreading of Petroleum.” Journal of Contaminant Hydrology 57:281-302.

Li D, and AW Neumann. 1990. "A Reformulation of the Equation-of-State for Interfacial-Tensions." Journal of Colloid and Interface Science 137:304-307.

Maupin GW. 2000. Investigation of Test Methods, Pavements, and Laboratory Design Related to Asphalt Permeability. VTRC 00-R24, Virginia Transportation Research Council, Charlottesville, Virginia.

McBride JF, CS Simmons, and JW Cary. 1992. "Interfacial spreading effects on one-dimensional organic liquid imbibition in water-wetted porous media." Journal of Contaminant Hydrology 11:1-25.

Simmons CS, and JM Keller. 2003. Status of models for land surface spills of nonaqueous liquids. PNNL-14350, Pacific Northwest National Laboratory, Richland, Washington.

Theriault J-Marc, JO Jensen, A Samuels, A Ben-David, C Gittings, and W Marinelli. 2001. "Passive Standoff Detection of Surface Contaminants: Modeling the Spectral Radiance." In Proceedings of the SPIE Conference on Instrumentation for Air Pollution and Global Atmospheric Monitoring, Boston MA, October 31 - November 2, 2001.

U.S. Coast Guard (USCG). Chemical Hazards Response Information System (CHRIS). [Online report]. Available URL: http://www.chrismanual.com/findform.htm.

U.S. Department of Commerce (USDC). Laboratory Investigation of Regional Liquid Organics From Spills, Leaks, and the Disposal of Hazardous Wastes in Groundwater. 1989. Publ. PB90-235797. Yaws CL, ed. 1999. Chemical Properties Handbook. McGraw-Hill, New York. 
Young SJ. 2001a. "Analysis of the High-Altitude SHARP Collection RECLUSE/ MO1/ September 2000” Aerospace Report No. ATR-2001 (8407)-3, 22 January 2001.

Young SJ. 2001b. "Analysis of the High-Altitude SHARP Collection RECLUSE/ MO1/ June 2000" Aerospace Report No. ATR-2001 (8407)-4, 22 January 2001.

Zisman WA. 1964. "Relation of the Equilibrium Contact Angle to Liquid and Solid Constitution." In Contact Angle, Wettibility, and Adhesion, ed. RF Gould, Advances in Chemistry Series 43, American Chemical Society, Washington, D.C. 


\section{Appendix A}

Gravity Current Combined with Infiltration 


\section{Appendix A}

\section{Gravity Currents Combined with Infiltration}

The concept of a two-dimensional gravity current spreading over an inclined-plane surface was discussed extensively by Lister (1992). Hussein et al. (2002) identified gravity-current theory as a possible way to predict the spreading of oil spills and discussed the equation derived by Lister (1992), but they never implemented an exact solution method. Nearly all ground surfaces and pavements are likely to be at least somewhat porous and permeable. That is, some of the liquid spilled on these surfaces will infiltrate and be imbibed. To treat the spreading of a liquid on a rough surface is no less theoretically simple than calculating the movement over a highly permeable medium such as a soil, sand, or gravel. Both problems involve loss of the surface liquid volume entering the substrate. This constitutes a new feature of the theory for which the steady removal of the spreading-liquid volume must be accounted for while the surface liquid spreads. In other words, unless the surface is absolutely impermeable, it is necessary to model infiltration coupled with spreading.

Acton et al. (2001) demonstrated coupling of a one-dimensional viscous gravity current with infiltration into a relatively deep porous medium. They applied a relatively simple infiltration model known in hydrology work as the Green-Ampt infiltration equation. The use of the Green-Ampt model to treat hydrological water balance associated with overland water flow is still a current research subject (Leonard et al. 2001). The Green-Ampt model is a simplified way of treating the complicated highly nonlinear problem of estimating unsaturated infiltration into a soil surface. The model uses the boundary condition of the height of liquid standing over the porous surface, which makes its formulation ideal for the situation of a gravity current, which is mainly characterized by its varying height as the liquid spreads.

Calculating a one-dimensional viscous gravity current coupled to Green-Ampt infiltration was discussed and demonstrated by Simmons and Keller (2003). The model and method were extended to twodimensions with a sloping surface by using Lister's equation (1992). Moreover, the case of a shallow porous surface, which is essential like a rough surface, could be treated by simply limiting the penetration depth in the Green-Ampt infiltration model. It is noteworthy to mention that Hussein et al. (2002) employed some basic equations that describe the extent of spreading in the two main directions of downslope and transverse liquid movement. These equations are general consequences of Lister's gravity-current equation. These equations were further modified in an ad hoc manner to account for liquid volume reduction as spreading proceeded over a porous surface. However, there is no theoretical justification for the accuracy of applying these equations for the spreading extent as was done. The method was at best a simplified conceptualization of the coupled processes. Here we have derived an exact mathematical formulation and solved the resulting equation to obtain a precise description of the spreading process. This theory describes the dynamical approach to the final liquid distribution both above and below the surface. The spreading is mainly controlled by gravity via the weight (density) and by the liquid's viscosity. If the surface is only rough and relatively impermeable so that only a minor volume fraction enters the substrate, then surface tension and adhesion as reflected by an effective contact angle will determine the final liquid height for which equilibrium would be achieved. That is, in the first sections of this report addressing spills on pavements, it was assumed that dynamical spreading stopped 
when a possible equilibrium distribution was achieved. This assumption required that no further infiltration could occur as a result of the limited porous depth. In general circumstances, the spreading ceases when all the liquid is infiltrated; and then the surface liquid height has vanished. Note that a simple rule was discovered in the first sections of this report: the spreading area is essentially determined as proportional to the volume spilled, provided the final liquid height can be estimated. That height is approximately invariant over spill volume for a given liquid and surface material as characterized by surface tension and contact angle. However, this rule does not apply when the wetting adhesion continues to change with time of contact. In this situation, a physical process of creeping spreading was observed that could not be described with the presented physical theory. In general, however, unless the surface is relatively impermeable (a pavement) over the spatial and time scale involved for the particular size of spill, most situations will likely be limited by the complete imbibing of the spilled liquid. Then Lister's gravity-current equation is most usually applicable. A further important aspect of spill spreading prediction is that the volume-is-proportional-to-area rule tells nothing about the shape of the final distribution. The dynamical equation presented below is required to predict the distribution.

Lastly, note that the theory given here applies only to stable or evenly spreading phenomena. A form of unstable spreading, especially on sloped surfaces, is known to occur for certain liquid property and surface combinations, which produce unpredictable fingering protrusions. Slight imperfections in surface smoothness can trigger and guide the finger advances when unstable conditions prevail. An example of this phenomenon was shown for brake fluid and mineral oil on water-wetted concrete. A spill of water on asphalt typically produces this pattern of behavior, especially on even a slightly tilted surface. It is associated with the fact that water has a high surface tension and does not adhere immediately to the surface - it beads or forms rivulets. This phenomenon is not addressed by the presented theory.

The equations for a viscous gravity current combined with simplified infiltration involving regular surface spreading (not unstable) are the following. (A reader should consult Lister's [1992] paper for his original formulation, which is modified here.)

$$
\frac{\partial}{\partial t} h=R \cdot\left[\frac{\partial}{\partial x}\left[h^{3} \cdot\left(\frac{\partial}{\partial x} h\right)\right]+\frac{\partial}{\partial y}\left[h^{3} \cdot\left(\frac{\partial}{\partial y} h\right)\right]-\gamma \cdot\left(\frac{\partial}{\partial x} h^{3}\right)\right]-K \cdot \frac{\left(h+h_{f}+z\right)}{z}
$$

where $\mathrm{R}=\frac{\rho \cdot \mathrm{g}}{3 \cdot \mu} \cdot \cos (\theta)$ and $\gamma=\tan (\theta)$.

The terms in Equation A.1 have the following definitions.

Defined physical parameters are:

$\rho=\operatorname{density}(\mathrm{gram} / \mathrm{ml})$

$\mu=$ viscosity (poise)

$\mathrm{k}=$ permeability $($ sq. $\mathrm{cm})$ 
$\mathrm{q}=$ Quantity $\mathrm{Q}$ per $(\mathrm{sec})^{\wedge} \alpha$

$\alpha=$ input rate parameter (unitless)

$\theta=$ slope angle in radians

$\phi=$ substrate porosity

$\mathrm{hf}=$ suction head at front $(\mathrm{cm})$

Variables:

$\mathrm{x}, \mathrm{y}$ are space coordinates on the tilted surface

$\theta$ is angle of surface tilt

$\mathrm{t}$ is time

$\mathrm{h}$ is spill height or head above surface (normal to surface)

$\mathrm{z}$ is depth of infiltrated below surface

Note the hydraulic conductivity $\mathrm{K}$ is

$$
\mathrm{K}=\frac{\mathrm{k} \cdot \rho \cdot \mathrm{g}}{\mu}
$$

Equation A.1 is solved subject to the following input condition

$$
\iint(h+\phi \cdot z) d x d y=q \cdot t^{\alpha}
$$

The Green-Ampt model used in Equation A.1 is

$$
\phi \cdot\left(\frac{\partial}{\partial \mathrm{t}} \mathrm{z}\right)=\mathrm{K} \cdot \frac{\mathrm{h}+\mathrm{h}_{\mathrm{f}}+\mathrm{z}}{\mathrm{z}}
$$

It is advantageous to transform Equations A.1 through A.3 into dimensionless form by scaling the variables. Scales are defined by

Length:

$$
L=\kappa\left(\frac{1}{2} \cdot \frac{3 \cdot \alpha+1}{\alpha-5}\right) \frac{-2}{\alpha-5}
$$


Spill height scale $\eta \cdot L$ :

Time scale:

$$
\eta=\kappa^{\left(\frac{-1}{2} \cdot \frac{3+\alpha}{a-5}\right)} \cdot r^{\frac{1}{\alpha-5}}
$$

$$
\mathrm{T}=\frac{1}{\eta^{3} \cdot \mathrm{L} \cdot \mathrm{R}}
$$

where $\kappa=\frac{3 \cdot \mathrm{k}}{\cos (\theta)}$ and $\mathrm{r}=\frac{\mathrm{q}}{\mathrm{R}^{\alpha}}$.

In terms of the scale factors $L, \eta$, and $T$, the variables of spreading are $t^{\prime}=t / T, x^{\prime}=x / L, y^{\prime}=y / L$, $h^{\prime}=h /(\eta L)$, and $z^{\prime}=z /(\eta L)$. Note that scale factors defined above have been defined to make the scaled input rate and conductivity equal to unity:

Thus, $\mathrm{K}^{\prime}=\frac{\mathrm{K}}{\mathrm{R} \cdot \mathrm{L}^{2} \cdot \eta^{4}}$ and $\mathrm{q}^{\prime}=\mathrm{q} \cdot \frac{\mathrm{T}^{\alpha}}{\left(\eta \cdot \mathrm{L}^{3}\right)}$ are made equal to one in the solution of Equation A.1.

In terms of the scaled variables, the equations to be solved are now

$$
\begin{gathered}
\frac{\partial}{\partial \mathrm{t}^{\prime}} \mathrm{h}^{\prime}=\left[\frac{\partial}{\partial \mathrm{x}^{\prime}}\left[\mathrm{h}^{\prime^{3}} \cdot\left(\frac{\partial}{\partial \mathrm{x}^{\prime}} \mathrm{h}^{\prime}\right)\right]+\frac{\partial}{\partial \mathrm{y}^{\prime}}\left[\mathrm{h}^{3} \cdot\left(\frac{\partial}{\partial \mathrm{y}^{\prime}} \mathrm{h}^{\prime}\right)\right]-\frac{\gamma}{\eta} \cdot\left(\frac{\partial}{\partial \mathrm{x}^{\prime}} \mathrm{h}^{3}\right)\right]-\frac{\left(\mathrm{h}^{\prime}+\mathrm{h}_{\mathrm{f}}^{\prime}+\mathrm{z}^{\prime}\right)}{\mathrm{z}^{\prime}} \\
\phi \cdot \frac{\partial}{\partial \mathrm{t}^{\prime}} \mathrm{z}^{\prime}=\frac{\left(\left(\mathrm{h}^{\prime}+\mathrm{h}_{\mathrm{f}}^{\prime}+\mathrm{z}^{\prime}\right)\right.}{\mathrm{z}^{\prime}} \\
\iint\left(\mathrm{h}^{\prime}+\phi \cdot \mathrm{z}^{\prime}\right) \mathrm{dx^{ \prime }} d \mathrm{y}^{\prime}=\mathrm{t}^{\prime \alpha}
\end{gathered}
$$

Equations A.4 through A.6 are nearly independent of any physical parameters, except porosity, wetting front suction, and the factor, $\gamma / \eta$, which describes the influence of gravity and slope. Generally, the wetting front suction is neglected or assumed zero unless specifically known. Notice that if there is no slope, then there is only one invariant set of equations to solve in terms of scaled variables. On the other hand, if there is no infiltration, then the entirely over-the-surface spreading equation can be made entirely invariant again as originally shown by Lister (1992). Thus, the presence of surface slope in the problem breaks the complete invariance of the spreading equation. Note that the dimensionless $\eta$ occurs because the liquid-height scale needs to be smaller than that for the spill extent. In particular, spills cover large areas in comparison to their height.

In implementing a numerical solution of Equations A.4 through A.6, it is essential to recognize that the condition (Equation A.6) is limited to some final value on the right-hand side corresponding to when the spill input is complete. That is, q in Equation A.2 is set to zero after the duration of the spill, and Equation A.2 does not actually hold for all time as the condition suggests. 
The Equation A.4 is solved by dividing the $\mathrm{x}$, $\mathrm{y}$ domain into cells with computation nodes or locations at the cell corners. A system of finite difference equations over nodes (or grid points) is obtained to be solved for each time. The solution is advanced in time by small time intervals or steps. Because Equation A.4 is highly non-linear, similar to Richard's equation for unsaturated infiltration into soil, various techniques must be implemented to obtain an accurate approximate numerical solution. Notice first that it is possible to introduce a flux potential like variable as

$$
\psi=\frac{1}{4} \cdot \mathrm{h}^{\prime 4} \text { so that } \frac{\partial}{\partial \mathrm{x}^{\prime}} \psi=\mathrm{h}^{\prime 3} \cdot\left(\frac{\partial}{\partial \mathrm{x}^{\prime}} \mathrm{h}^{\prime}\right) \text { and so forth for } \mathrm{y}^{\prime}
$$

This transformation facilitates solving the problem with methods like those discussed by Campbell (1985) in his soil physics text. The node equations are put in a form that is completely or inherently mass conservative, meaning that the entire spilled volume is always accurately accounted for in the numerical finite difference scheme. At each time, the non-linear volume balance equations are solved using a Newton-Raphson iteration procedure. Further, the system of difference equations is solved by using an alternating-direction implicit (ADI) method for a parabolic type of partial differential equations. These finite-difference solution methods are described well in the Schaum's Outline Series by DuChateau and Zachmann (1986). During the solution, for each time step, the spill input and infiltration extraction are treated as sink terms in the Equation A.4. Liquid removed from above the surface according to Equation A.5 or Equation A.3 appears as the distribution of $\mathrm{z}$.

As an example, consider the spill of $10 \mathrm{gal} / \mathrm{sec}$ over a period of 10 seconds on a surface with permeability $\mathrm{k}=10^{-6} \cdot \mathrm{cm}^{2}$ The liquid is water; 100 gal is spilled. The spill release is linear in time for alpha equal unity. The incline angle is 5 degrees. Using these values, the length scale $\mathrm{L}$ is $1965 \mathrm{~cm}$, and the height scale is $1.85 \mathrm{~cm}$; the time scale $\mathrm{T}$ is $18.8 \mathrm{sec}$. A porosity of 0.4 is used also. The permeability employed here represents a sand medium, with fairly high conductivity, as the example simulation will demonstrate. Note that after solving the problem in terms of scaled variables, the actual values can be recovered by multiplication of predictions by the scales of length and time.

The simulation of the scaled solution surface, $h(x, y, t)$ and $z(x, y, t)$, is shown in Figures A.1 and A.2. The distance, height, and depth are scaled and are relative values. On the same scale, it is apparent that the depth of infiltration is much greater than the liquid height at 10 seconds. Figure A.3 shows relative volumes above and below the surface over the simulation period which is about 20 seconds. The liquid has infiltrated and disappeared entirely from the surface by about 14 seconds, or 0.75 scaled time on Figure A.3. At slightly after 10 seconds, the spill height is $0.3 \mathrm{~cm}$, and the infiltration depth average is $2.36 \mathrm{~cm}$. 


\section{Spill on Surface at Specified Time - (half region shown}

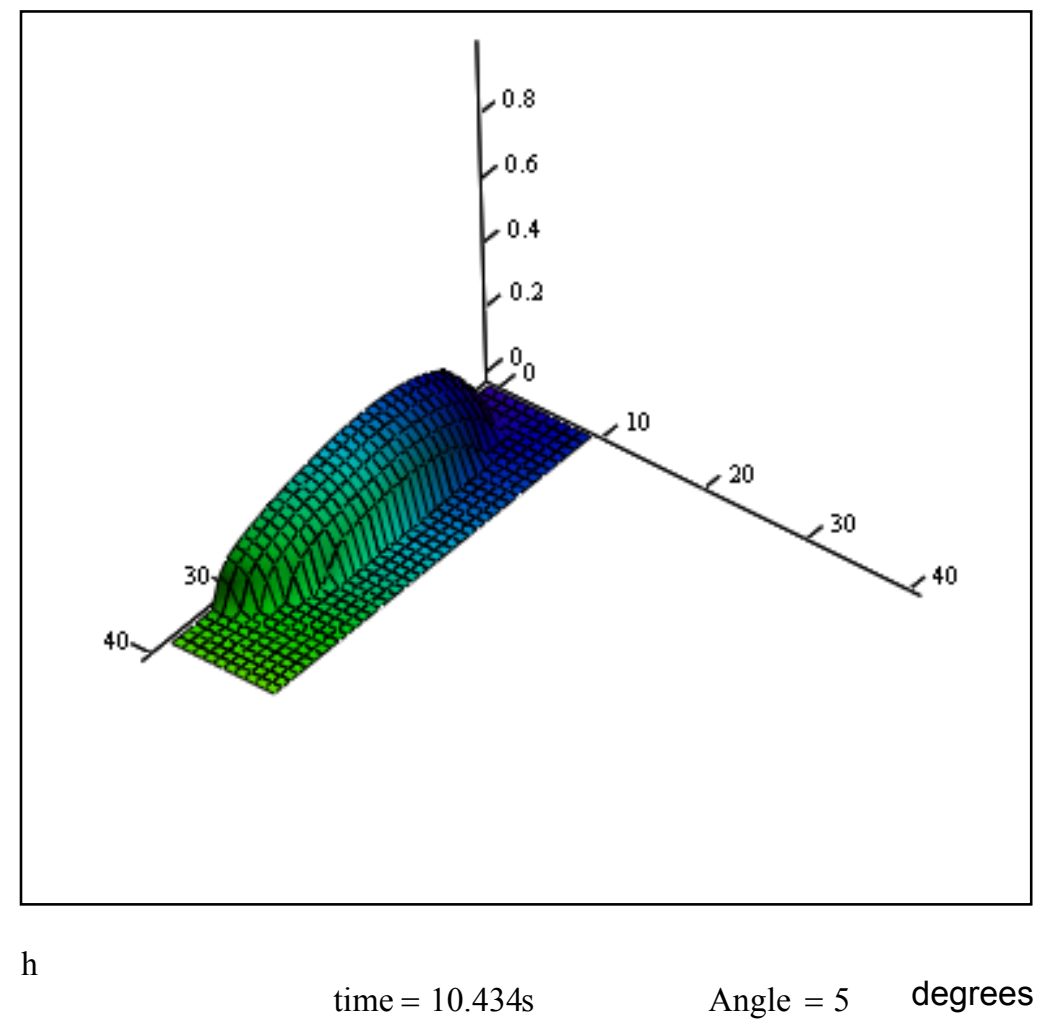

Figure A.1. Scaled Height above Surface for an Example Spill. The height surface (h solution of Equation A.4) is given on a grid of 40 by 11 nodes, and distances are in scaled units.

Downslope is toward the left lower corner. The time is slightly after completion of the spill.

After the spill release is completed, the maximum area covered on the surface at any time is 30 square meters, while the surface wetted by the liquid infiltrated marks a greater area of 40 square meters. Because the liquid height on the surface entirely vanishes after 14 seconds, the only way the wetted area could be detected is from the spreading area covered below the surface. The below-surface area traces everywhere the surface spill has infiltrated, while it moves downslope with diminishing volume. The time that would be available to detect the spill just below the surface would ultimately be controlled by the subsurface drainage rate and by how long the liquid is retained near the surface by capillarity of the medium. 


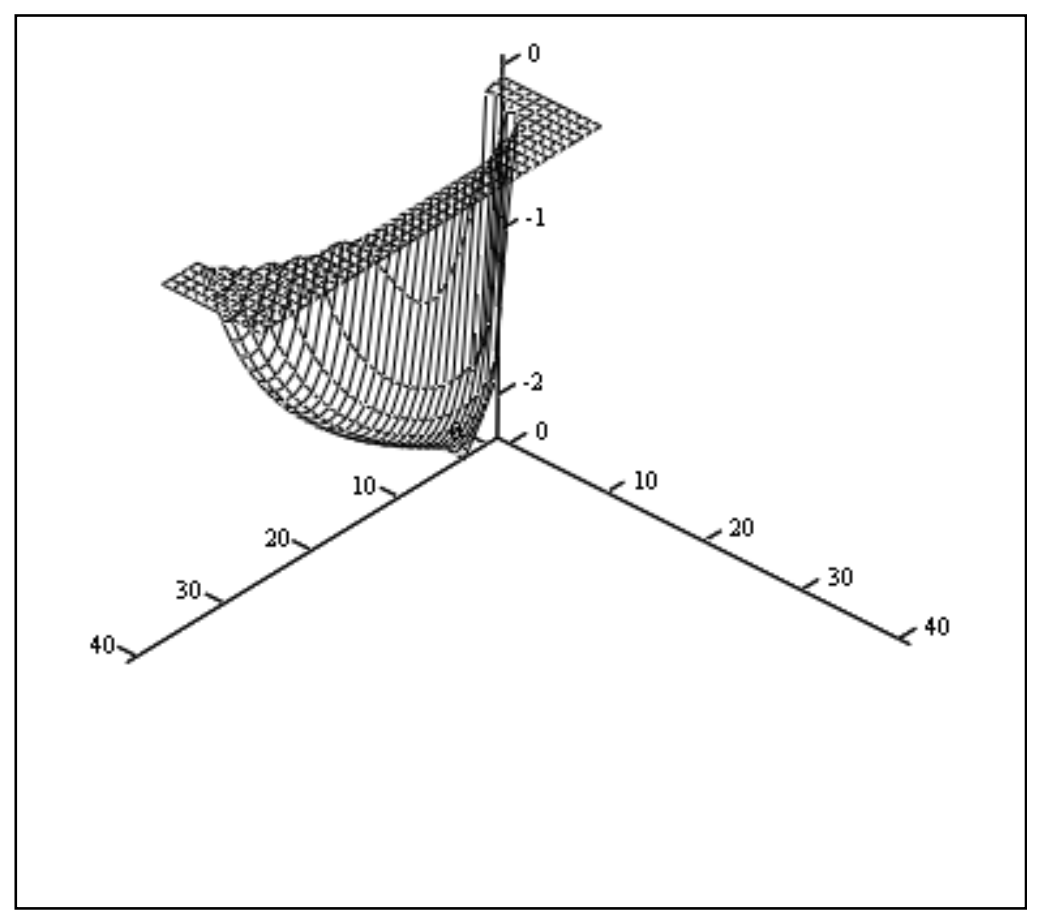

depth

Figure A.2. Scaled Depth of Infiltration below Surface for Example Spill

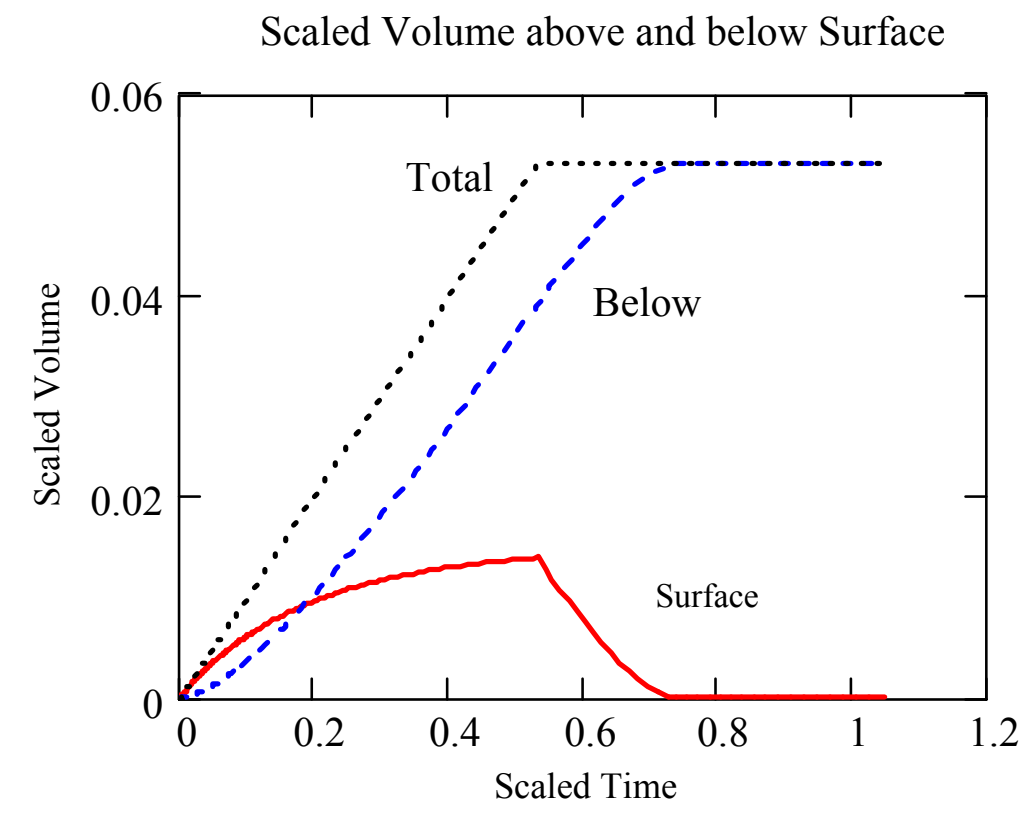

Figure A.3. Scaled Volume of Spill Above and Below Surface 


\section{A.1 References}

Acton JM, HE Huppert, and MG Worster. 2001. “Two-Dimensional Viscous Gravity Currents Flowing Over a Deep Porous Medium.” J. of Fluid Mech., 440:359-380.

Campbell GS. 1985. "Soil Physics with Basic Transport Models for Soil-Plant Systems." Elsevier Science Publ., New York.

DuChateau P, and DW Zachmann. 1986. "Partial Differential Equations.” Schaum's Outline Series, McGraw-Hill, Inc., New York.

Leonard J, E Perrier, and G de Marsily. 2001. "A Model for Simulating the Influence of a Spatial Distribution of Large Circular Macropores on Surface Runoff." Water Resources Research $37: 12,3217-3225$.

Lister JR. 1992. "Viscous Flows Down an Inclined Plane from Point and Line Sources." J. Fluid Mech. 242:631-653. 


\section{Distribution}

No. of

Copies

OFFSITE

5 NGA

1200 First St. SE

Washington DC 20303

Attn: Bryan Albers, MS N-06

No. of

Copies

ONSITE

15 Pacific Northwest National Laboratory

J. L. Hylden (10) K8-41

C.S. Simmons (3) K9-33

J.M. Keller (2) K9-36

Distr. 1 